\title{
Article \\ Comparative Study of the Sensitivity of PLA, ABS, PEEK, and PETG's Mechanical Properties to FDM Printing Process Parameters
}

\author{
Mohammed Algarni ${ }^{1, *(D)}$ and Sami Ghazali ${ }^{2}$ \\ 1 Mechanical Engineering Department, Faculty of Engineering, King Abdulaziz University, P.O. Box 344, \\ Rabigh 21911, Saudi Arabia \\ 2 Mechanical and Materials Engineering Department, Faculty of Engineering, University of Jeddah, \\ P.O. Box 80327, Jeddah 21589, Saudi Arabia; sghazali@uj.edu.sa \\ * Correspondence: malgarni1@kau.edu.sa; Tel.: +966-569440440
}

Citation: Algarni, M.; Ghazali, S. Comparative Study of the Sensitivity of PLA, ABS, PEEK, and PETG's Mechanical Properties to FDM Printing Process Parameters. Crystals 2021, 11, 995. https://doi.org/ $10.3390 /$ cryst 11080995

Academic Editors: Assem Barakat and Alexander S. Novikov

Received: 17 July 2021

Accepted: 18 August 2021

Published: 21 August 2021

Publisher's Note: MDPI stays neutral with regard to jurisdictional claims in published maps and institutional affiliations.

Copyright: (C) 2021 by the authors. Licensee MDPI, Basel, Switzerland. This article is an open access article distributed under the terms and conditions of the Creative Commons Attribution (CC BY) license (https:// creativecommons.org/licenses/by/ $4.0 /)$.

\begin{abstract}
Significant advances in fused deposition modeling (FDM), as well as its myriad applications, have led to its growing prominence among additive manufacturing (AM) technologies. When the technology was first developed, it was used for rapid prototyping to examine and analyze a product in the design stage. FDM facilitates rapid production, requires inexpensive tools, and can fabricate complex-shaped parts; it, therefore, became popular and its use widespread. However, various FDM processing parameters have proven to affect the printed part's mechanical properties to different extents. The values for the printing process parameters are carefully selected based on the part's application. This study investigates the effects of four process parameters (raster angle, layer thickness, infill percentage, and printing speed) on the mechanical behavior of printed parts that are based on available literature data. These process parameter's influence on part's mechanical properties varies depending on the FDM material. The study focuses on four FDM materials: polylactic acid (PLA), acrylonitrile butadiene styrene (ABS), polyether ether ketone (PEEK), and polyethylene terephthalate glycol (PETG). This paper summarizes the state-of-the-art literature to show how sensitive the material's mechanical properties are to each process parameter. The effect of each parameter on each material was quantified and ranked using analysis of variance (ANOVA). The results show that infill percentage then layer thickness are the most influential process parameter on most of the material's mechanical properties. In addition, this work identifies gaps in existing studies and highlights opportunities for future research.
\end{abstract}

Keywords: fused deposition modeling; additive manufacturing; ANOVA; mechanical properties; process parameters; PLA; ABS; PEEK; PETG

\section{Introduction}

Additive manufacturing (AM) via fused deposition modeling (FDM) is a novel method for building parts layer by layer using CAD models that enables one to build parts of various complexities promptly and inexpensively. AM offers reliable, flexible, and costeffective manufacturing methods because it does not require any tooling and minimizes material wastage [1]. 3D printing has become a popular manufacturing method in various industries, including aerospace, defense, automobile, biomedical, and dental [2,3]. Broad industrial adoption of FDM technology is driven by cost reductions, enhanced mechanical properties, high dimensional accuracy, and manufacturing speed. FDM consists of extruding polymer and polymer composite materials through a hot nozzle to form a raster with various shapes, thicknesses, widths, and heights, as shown in Figure 1a. The rasters are combined layer by layer until the whole part is complete. The printing process parameters are set to influence the parts' properties and improve the quality and processing time. FDM process parameters can be categorized into slicing parameters, build orientation, 
and temperature conditions [4]. Slicing parameters include many variables such as layer thickness, extrusion width, flow rate, deposition speed, air gap, and raster angle. Build orientation is defined by the specimen's orientation (vertical, horizontal, lateral, or some other orientation). Temperature conditions such as environment, extrusion, and bed temperatures affect the bonding of the fabricated part and thus influence its mechanical properties. Since process parameters can vary, anisotropic behavior plays a crucial role in fabricated parts [5-9]. Many researchers are working on optimizing the printing process parameters used in fabricating FDM parts [6,7,9-11]. A thorough investigation of 3D printed part's mechanical properties would help manufacturers to predict printed part's mechanical behavior based on the process parameters selected. This requires an extensive investigation optimizing the set of process parameters to produce parts with desired qualities [12,13].
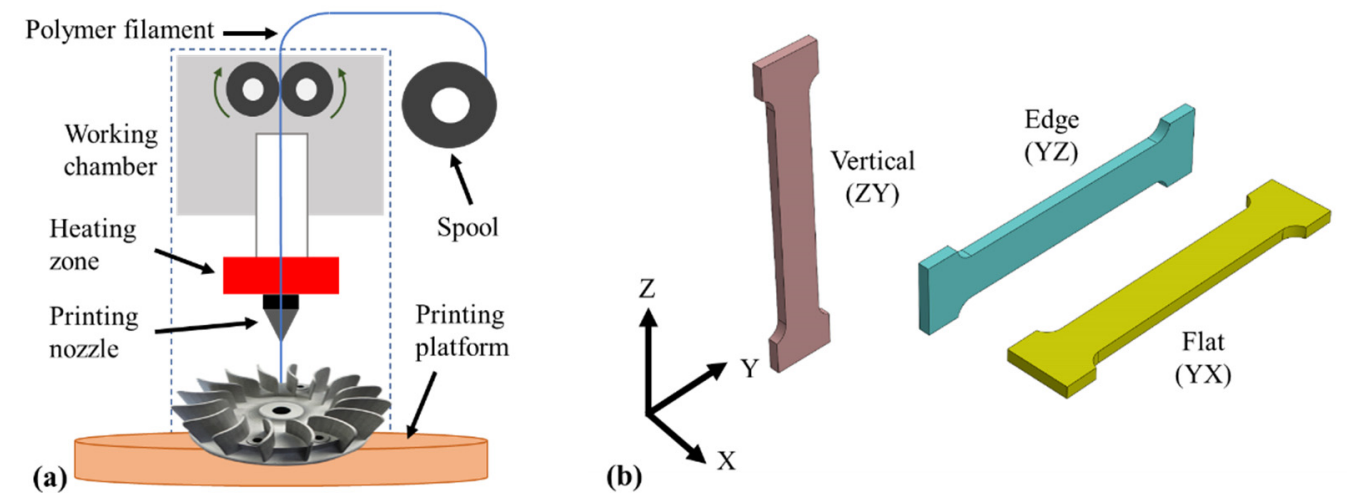

Figure 1. (a) FDM schematic diagram and (b) build orientation.

The process parameters that most significantly influence the mechanical properties of FDM fabricated parts are layer thickness, raster width, infill percentage, raster angle, and build orientation [14-17]. Earlier studies have optimized these process parameters via numerous optimization methods and techniques to improve the part's mechanical properties. Ahn et al. [18] studied the anisotropic material properties of FDM using acrylonitrile butadiene styrene (ABS) to formulate building rules for designing FDM parts based on experimental results. Bakar et al. investigated the effects of raster width, layer thickness, and contour width on the surface finish and accuracy of fabricated parts [19]. A study conducted by Rajpurohit et al. [20] found that layer thickness and raster angle are significant parameters in fabricating polylactic acid (PLA) parts. Furthermore, another study concluded that layer thickness and infill percentage are the most significant parameters when designing parts made of ABS material [21]. Other studies were conducted to determine the effects of raster angle, raster width, raster shape, infill percentage, infill pattern, printing speed, layer thickness, air gap, build orientation, and the number of contours on various mechanical properties [13,22-30]. Rayegani and Onwubolu used a differential evolution approach to process parameters to optimize part's tensile strength only [31]. Other researchers have focused on optimizing multiple properties, yet the property optimization was done separately $[14,32,33]$. More advanced research has focused on optimizing two or more properties simultaneously to attain an optimum set of process parameters [34-36].

PLA has been extensively investigated. Numerous studies have experimentally investigated how the PLA part's mechanical properties are affected by raster angle [37-40]. Other studies have investigated the influence of layer thickness on the PLA part's mechanical properties such as tensile strength, flexural strength, elastic modulus, shear stress, and impact strength [32,41-46]. Moreover, infill percentage and printing speed's effects on PLA mechanical properties were examined in $[44,45,47,48]$. Raster angle and layer thickness influence on the mechanical properties of ABS parts have also been investigated [49-51]. Furthermore, the ABS part's mechanical properties are affected by infill percentage and printing speed [52-54]. 
Additionally, raster angle and layer thickness influence on the mechanical properties of parts made of polyether ether ketone (PEEK) has been examined $[15,55,56]$. Similarly, the effects of infill percentage and printing speed on PEEK part's mechanical properties have been investigated [57-59]. The mechanical properties of PEEK parts are also affected by different infill percentages, speeds, and patterns [60,61]. Fewer studies have examined polyethylene terephthalate glycol (PETG) because it is still in the investigation and development process. However, the influence of raster angle and layer thickness on the mechanical behavior of PETG parts have been investigated $[62,63]$.

This research presents a comparative evaluation of the FDM process parameter's influence on the mechanical properties of parts made of PLA, ABS, PEEK, and PETG in similar experimental conditions. The mechanical properties and printing characteristics of the polymers are listed in Table 1. ANOVA was used to evaluate the effects of four most commonly used process parameters (raster angle, layer thickness, infill percentage, and printing speed) on part's mechanical properties. The influence of each process parameter was quantified and ranked based on ascending variance values obtained via ANOVA. Finally, this paper identifies research gaps to guide future work towards making the FDM process more reliable.

Table 1. Mechanical properties and printing characteristics of different FDM materials.

\begin{tabular}{ccccc}
\hline Properties & PLA & ABS & PEEK & PETG \\
\hline Extrusion temperature $\left({ }^{\circ} \mathrm{C}\right)$ & $190-210$ & $220-260$ & $380-410$ & $230-250$ \\
Bed platform Temp $\left({ }^{\circ} \mathrm{C}\right)$ & $25-80$ & $90-110$ & $90-150$ & $60-80$ \\
Density $\left(\mathrm{g} / \mathrm{cm}^{3}\right)$ & 1.25 & 1.04 & 1.30 & 1.23 \\
Tensile strength $(\mathrm{MPa})$ & 65 & 43 & 100 & 49 \\
Flexural strength $(\mathrm{MPa})$ & 97 & 66 & 170 & 70 \\
Izod impact strength $\left(\mathrm{kJ} / \mathrm{m}^{2}\right)$ & 4 & 19 & 7 & 7.6 \\
Recyclability & Yes & Yes & Yes & Yes \\
Biodegradability & Yes & No & No & No \\
Fume toxicity & Very low & Medium & Low & Very low \\
\hline
\end{tabular}

\section{Printing Process Parameters}

AM consists of many technologies that create physical parts by the successive addition of materials. Various disciplines such as architecture, medicine, engineering, education, and entertainment use AM technologies. Due to the rapid development of AM technologies and their adoption by myriad disciplines, there are various terms for the various specific applications or areas of AM. To avoid confusion that might hamper communication among different disciplines, this section defines the various process parameters based on ASTM International standards [64-67]. These are the most common FDM printing process parameters, along with their variables and ranges:

1. Raster angle, sometimes called raster orientation, is the direction of the deposited layers with respect to the build platform. It usually ranges from $0^{\circ}$ to $90^{\circ}$. The deposited filaments exiting the 3D printer nozzle form rasters (extrusions) that can be constructed using various angles to fill the interior of the part being manufactured. Raster angle is an essential parameter for the FDM process as it influences the anisotropy of the parts $[18,68]$. Results reported in the literature illustrate that the raster angle significantly affects the mechanical properties of all materials to different extents. Generally, the tensile strength becomes higher once the raster direction is the same as the loading direction due to high anisotropy.

2. Layer thickness is the height of each deposited layer in the 3D printed product. A product's height is the sum of the thicknesses of the stacked layers extruded from the nozzle tip. It depends on the nozzle tip diameter and the filament material. Usually, it ranges from 0.07 to $0.4 \mathrm{~mm}$. The effect of layer thickness on strength and other mechanical properties is considerable. Generally, the experimental results show that flexural, tensile, and compression strength increase as layer thickness decreases, which 
leads to products being made of a greater number of layers. Consequently, increasing the layer number leads to increasing the process of reheating previous layers, which improves layer-to-layer diffusion. Also, the surface quality of the printed objects increases as layer thickness decreases [69].

3. Infill percentage, sometimes called infill density, describes the solidity of the invisible inner structure of a printed part. In other words, it describes the infill volume, which plays a major role in a printed part's strength and mass. Usually, it ranges between $20 \%$ and $100 \%$. Infill percentage is considered one of the leading parameters that significantly affect the part's mechanical properties [70]. For instance, the infill percentage determines the contact zone between the filament rasters and layers, which affects mechanical properties [14,71]. Studies show that infill percentage has a significant influence on mechanical properties. Their results indicate that mechanical properties improve as the infill percentage increases since the resistant section (transverse to the load) is smaller with lower infill percentages.

4. Printing speed is the nozzle's horizontal speed on the build platform during extrusion and deposition. It determines the total printing time. It depends on the printing technique (stereolithography (SLA), selective laser sintering (SLS), and FDM) and the filament material used. Typically, it ranges from 15 to $90 \mathrm{~mm} / \mathrm{s}$. The printing speed influences the material's spread and forming dimension more than all other FDM process parameters. High printing speeds result in over-extrusion on part edges and reduces extrusion width which leads to poor dimensional accuracy as additional layers are added before previous layers have completely solidified.

5. Extrusion temperature is defined as the heating temperature for a filament material in the nozzle section during the extrusion process. It varies depending on the thermoplastic material type and the printing speed. Extrusion temperature ranges are illustrated in Table 1.

6. Build orientation is defined as the posture/orientation of an object with respect to the Cartesian coordinate system directions while printing. Usually, the vertical posture is the ZY-plane, the edge posture is the YZ-plane, and the flat posture is the YX-plane as presented in Figure $1 b$.

7. The air gap is the gap between rasters on the same layer of a printed part. It usually ranges from 0 to $0.08 \mathrm{~mm}$. However, the air gap can also be negative (superposition of adjacent depositions) in $100 \%$ infill. The effects of air gap on mechanical properties of PLA parts can be low [72], while it can be relevant in ABS parts [73]. A negative air gap increases both strength and stiffness.

8. Raster width is the width of a single deposited raster and depends on the extrusion nozzle diameter, printing speed, and the ratio between printing speed and extrusion speed, which is called "extrusion multiplier" [74]. The calibration of this parameter is very important for part accuracy and mechanical properties. Usually, it ranges between 0.1 and $0.7 \mathrm{~mm}$.

9. Contour is the outer solid layer that encloses the printed part's inner infill structure. It corresponds to the number of solid outer layers. Usually, it ranges from 1 to 6 contours.

\section{Polylactic Acid (PLA)}

PLA is a biodegradable thermoplastic filament whose use in FDM has been increasing. It requires low energy and temperature (starting melting point: ${ }^{\circ} \mathrm{C}$ ) to be extruded and a moderately heated bed during deposition to make an object. As a result, PLA makes parts with higher tensile strength and lower ductility than other common materials. It is used in food packaging, cardiovascular implants, and dental scaffolds [24,55].

\subsection{Influence of Raster Angle}

Many experiments on PLA material suggest that the ultimate tensile strength (UTS) heavily depends on the raster angle [42,75,76]. Zhang et al. [77] studied the effects of raster 
angle on the mechanical properties of PLA parts produced using FDM. They concluded that raster angle significantly affects the different mechanical properties of PLA, as illustrated in Figure 2a-c. Algarni [37] investigated the effects of raster angle on PLA samples and concluded that the UTS was affected significantly by the raster angle such that it dropped by $36 \%$ when the raster angle changed from $0^{\circ}$ to $90^{\circ}$. Similarly, Young's modulus and elongation at break decreased by $9 \%$ and $14 \%$, respectively.
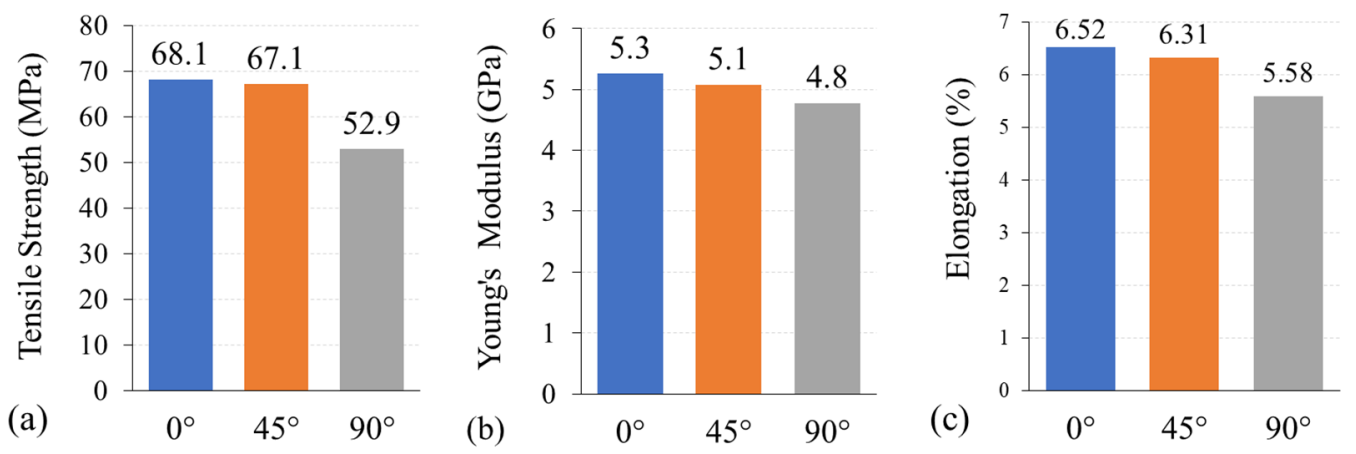

Figure 2. Influence of raster angle on PLA (a) tensile strength, (b) Young's modulus, and (c) \% elongation.

\subsection{Influence of Layer Thickness}

A study in [78] investigated the influence of different layer thicknesses on FDM dogbone shape specimens with $25 \mathrm{~mm}$ gauge length. The different layer thicknesses were 0.1 and $0.2 \mathrm{~mm}$, and three samples of each layer thickness were tested. Three distinct infill patterns were used, and the experimental results indicate that layer thickness significantly influenced all three pattern's load capacities, as shown in Figure 3a. Another study in [79] designed the specimens according to ASTM standard D368 and tested layer thicknesses that ranged from $(0.1-0.3 \mathrm{~mm})$ at three various extrusion speeds. The research results are presented in Figure 3b. Also, a study in [80] presented a novel mechanical model of different mechanical properties that can accurately predict the strength and Young's modulus of FDM PLA. The experimental data show a similar effect of layer thickness on strength while varying the raster angles in Figure $3 c$.
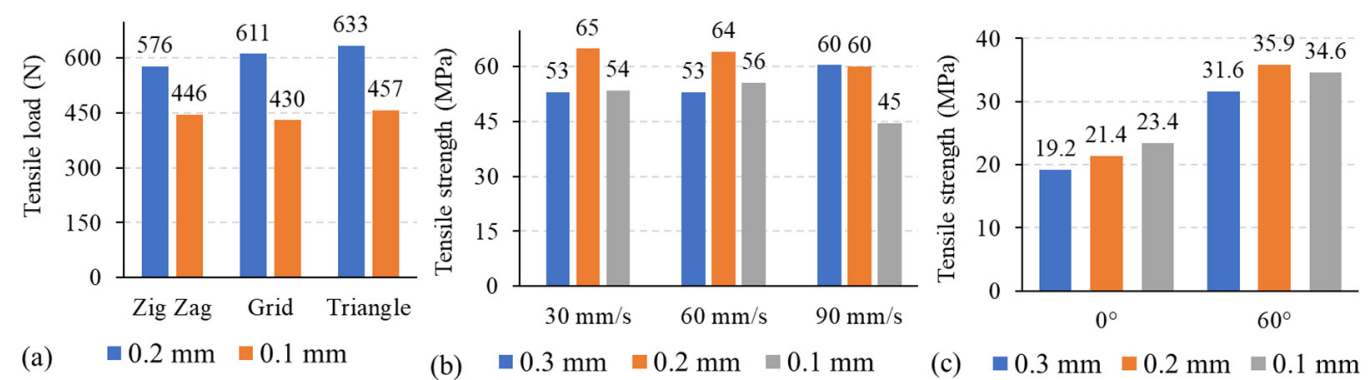

Figure 3. (a) PLA strength sensitivity to layer thickness (mm) with different infill patterns, (b) PLA strength sensitivity to layer thickness with different extrusion speeds (mm/s), and (c) PLA strength sensitivity to layer thickness with different raster angles (in degrees).

\subsection{Influence of Infill Percentage}

Panes et al. studied the effects of different manufacturing parameters on the mechanical behaviors of PLA parts fabricated via FDM methods [81]. The study concluded that increasing the infill percentage from $20 \%$ to $50 \%$ improved the UTS by $27 \%$, yield stress by $21 \%$, Young's modulus by $34 \%$ and elongation at break by $30 \%$. They also concluded that infill percentage influences these characteristics more than layer height and build orientation. A study by Rismalia et al. [82] shows that increasing the PLA infill percentage 
from $25 \%$ to $75 \%$ could enhance the UTS, yield strength, and the modulus of elasticity by $40 \%, 34 \%$, and $15 \%$, respectively.

\subsection{Influence of Printing Speed}

Different printing speeds have a significant influence on the material's spread and forming dimension. In small parts, high printing speed leads to material deformations due to new layers being placed on top of layers that have not yet fully solidified. Consequently, the weight of the new layer deforms the previous layer. Printing speed affects deposition width more than it does on the deposition height [83]. Furthermore, researchers have concluded that higher printing speed slightly decreases the tensile strength [84]. A study in [85] examined changes in tensile strength. As presented in Figure 4a, the results pertaining to the effects of printing speed on tensile strength concur with those of previous studies. A study in [48] studied the influence of the printing speed on PLA's Young's modulus. The study shows that different printing speeds $(70,80,90,100$, and $110 \mathrm{~mm} / \mathrm{s})$ do not change Young's modulus by more than $20 \%$. Additionally, higher printing speeds affect how the filament melts and causes poor layer-to-layer adhesion, which results in lower strength. Another study in [86] examined the influence of different printing speeds $(30,40$, and $50 \mathrm{~mm} / \mathrm{min})$ on the PLA's compressive strength. The resulting changes were insignificant, as shown in Figure $4 \mathrm{~b}$.

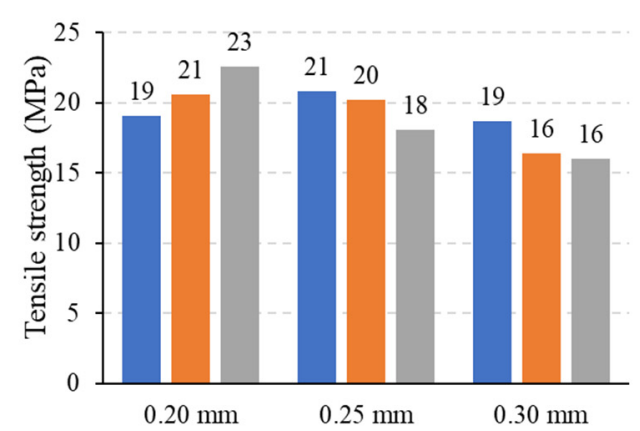

(a)

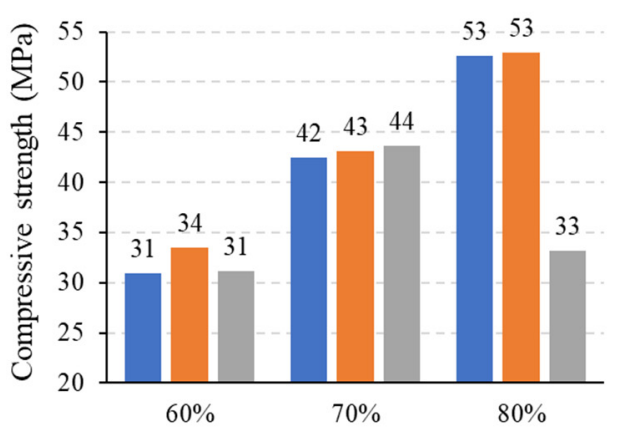

(b) $\square 30 \mathrm{~mm} / \mathrm{min} \backsim 40 \mathrm{~mm} / \mathrm{min} \backsim 50 \mathrm{~mm} / \mathrm{min}$

Figure 4. (a) PLA tensile strength sensitivity to printing speed with different layer thicknesses (in $\mathrm{mm}$ ) and (b) compressive strength sensitivity to printing speed with different infill percentages (in \%).

\subsection{PLA Mechanical Properties Sensitivity Study Using ANOVA}

The data above demonstrate that mechanical properties of PLA fabricated parts are affected by the process variables selected to different extents. ANOVA evaluates the variance between groups and was used to determine the effects of various process parameters (raster angle, infill percentage, printing speed, and layer thickness) on various material properties (Young's modulus, UTS, flexural strength, and elongation at break). ANOVA enables delineating the variance weights of different groups, which aids in understanding each process parameter's effect on different mechanical properties. The range for each process parameter is summarized in Table 2. Figure 5 shows that infill percentage and layer thickness significantly affect Young's modulus. UTS is affected mainly by infill percentage and raster angle. Flexural strength is greatly affected by infill percentage and printing speed. Elongation at break is determined by infill percentage and raster angle. The process parameters are ranked in Table 3 according to their respective influence on the specified PLA material properties. 
Table 2. Process parameters range used for PLA along with the related settings.

\begin{tabular}{ccccc}
\hline Process Parameter & Range Selected & Low & Middle & High \\
\hline Raster angle & $0^{\circ}-90^{\circ}$ & $0^{\circ}$ & $45^{\circ}$ & $90^{\circ}$ \\
Layer thickness & $0.1-0.3 \mathrm{~mm}$ & $0.1 \mathrm{~mm}$ & $0.2 \mathrm{~mm}$ & $0.3 \mathrm{~mm}$ \\
Infill percentage & $20-100 \%$ & $20 \%$ & $50 \%$ & $100 \%$ \\
Printing speed & $35-65 \mathrm{~mm} / \mathrm{s}$ & $35 \mathrm{~mm} / \mathrm{s}$ & $50 \mathrm{~mm} / \mathrm{s}$ & $65 \mathrm{~mm} / \mathrm{s}$ \\
\hline
\end{tabular}

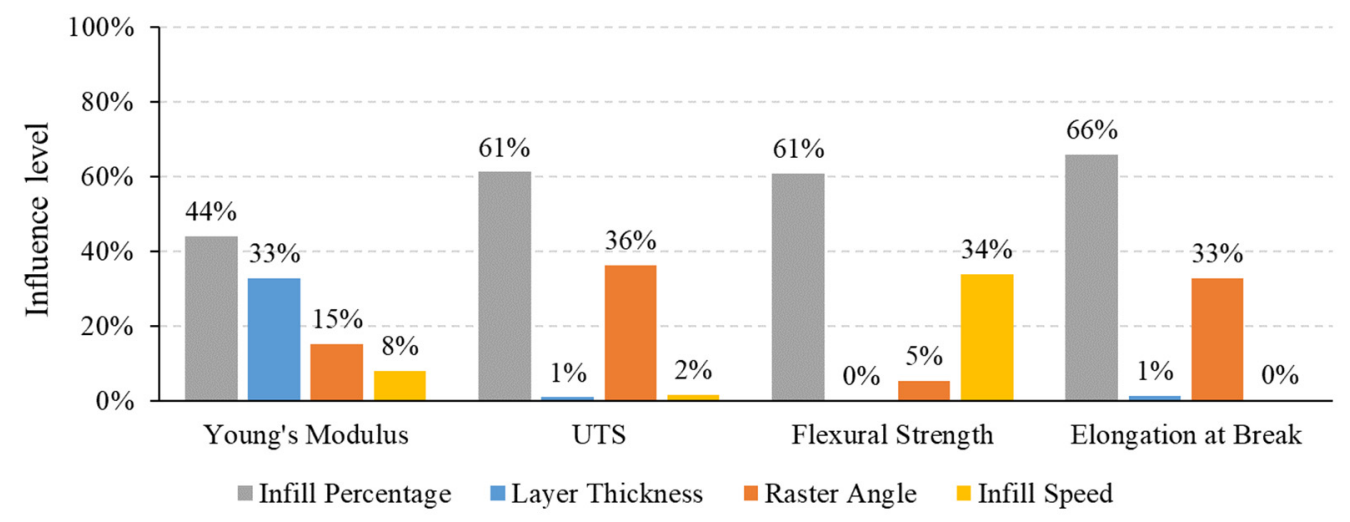

Figure 5. Process parameter's relative influence on PLA mechanical properties.

Table 3. Table ranking parameters according to influence on PLA mechanical properties as determined by ANOVA.

\begin{tabular}{|c|c|c|c|c|}
\hline Material Property & First & Second & Third & Fourth \\
\hline Young's Modulus & Infill Percentage & Layer Thickness & Raster Angle & Printing speed \\
\hline UTS & Infill Percentage & Raster Angle & Printing speed & Layer Thickness \\
\hline Flexural Strength & Infill Percentage & Printing speed & Raster Angle & Printing speed \\
\hline $\begin{array}{c}\text { Elongation at } \\
\text { break }\end{array}$ & Infill Percentage & Raster Angle & $\begin{array}{l}\text { Layer } \\
\text { Thickness }\end{array}$ & Printing speed \\
\hline
\end{tabular}

\section{Acrylonitrile Butadiene Styrene (ABS)}

ABS is an amorphous and thermoplastic polymer that is frequently utilized in FDM techniques. It is not biodegradable and yet is extruded at high temperatures. It is known for its superior impact resistance and toughness. It is used in computers, pipes, boats, and LEGO toys [55].

\subsection{Influence of Raster Angle}

Fatimatuzahraa et al. [87] studied the effects of different raster angles on the mechanical properties of FDM parts made of ABS material. They defined the raster angles as follows: axial $\left(0^{\circ}\right)$, crisscross $\left(45^{\circ} /-45^{\circ}\right)$, cross $\left(0 / 90^{\circ}\right)$, and transverse $\left(90^{\circ}\right)$. The cross and crisscross samples exhibited negligible differences in tensile strengths of $18.5 \mathrm{MPa}$ and 18.3 $\mathrm{MPa}$, respectively. Deflection tests indicated that crisscross samples could withstand about 3\% more elongation than cross samples. Furthermore, flexural test results indicated that crisscross samples are about $9 \%$ stronger than cross samples. Furthermore, impact tests revealed that crisscross samples have higher impact strength than cross samples. The findings of the study ae summarized in Figure 6a,b Additionally, Sood et al. [14] concluded that small raster angles would result in long rasters that will increase stress accumulation along the direction of deposition. However, small raster angles are inclined along the direction of loading, which improves the part's strength. Ziemian et al. [88,89] have also experimentally determined that raster should be aligned along the longest dimension to obtain the highest tensile and compressive strengths for ABS. 

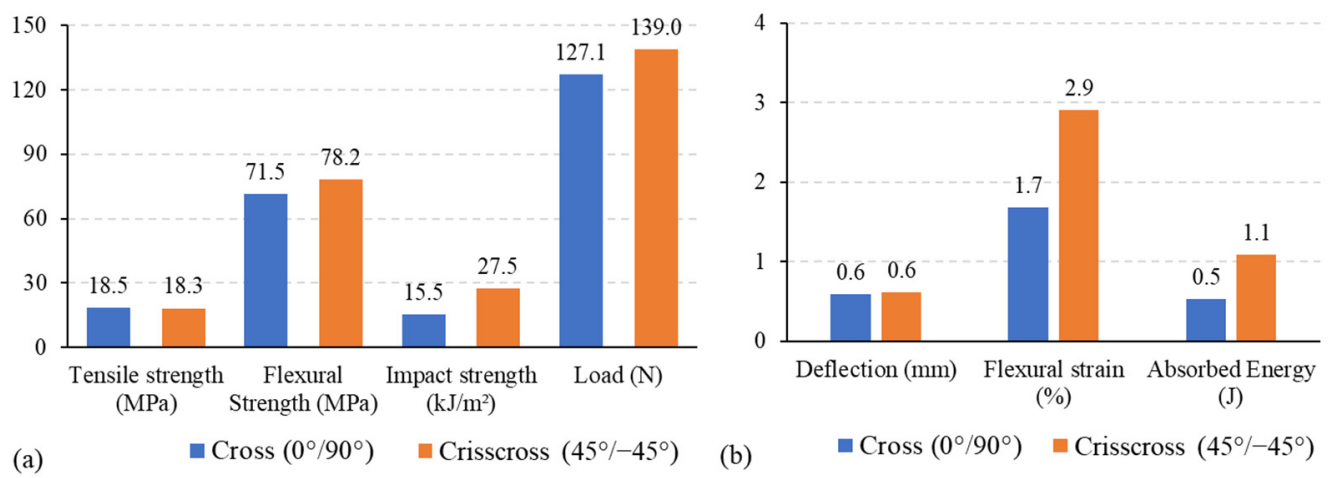

Figure 6. Effects of raster angle on different mechanical properties $(\mathbf{a}, \mathbf{b})$ of ABS.

\subsection{Influence of Layer Thickness}

A study in [90] experimentally examined material strength's sensitivity to different layer thicknesses in specimens designed as per ASTM standard D638. The layer thicknesses used were 0.2 and $0.4 \mathrm{~mm}$ and the raster angles were $0^{\circ}, 45^{\circ}$, and $90^{\circ}$. The results show a moderate effect, as presented in Figure 7a. A recent study in [91] studied how sensitive ABS tensile and compression strength are to layer thickness. The results show that tensile and compression strength decrease as layer thickness increases. Additionally, a study in [92] investigated the effects of different layer thicknesses with different infill percentages (Figure $7 \mathrm{~b}$ ). Unfortunately, the results do not follow a regular pattern and are difficult to interpret.

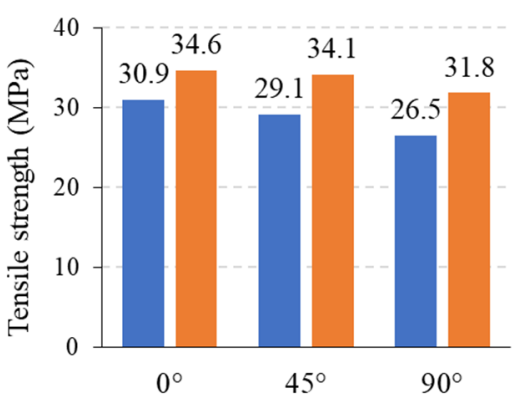

(a)

$\square 0.4 \mathrm{~mm}=0.2 \mathrm{~mm}$

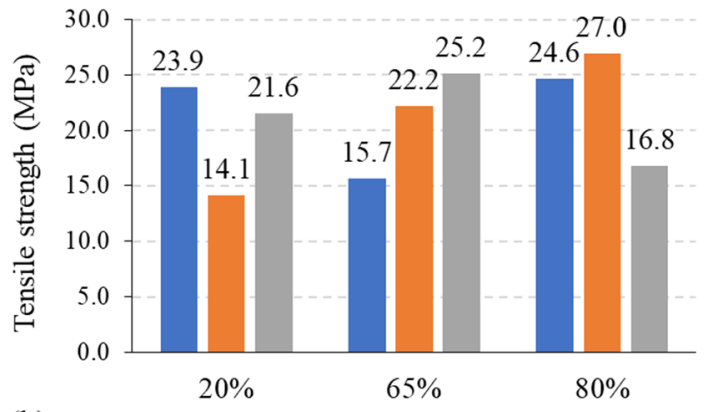

(b)

$\square 0.35 \mathrm{~mm} \quad \square 0.25 \mathrm{~mm} \quad 0.2 \mathrm{~mm}$

Figure 7. (a) ABS tensile strength sensitivity to layer thickness with different raster angles (in degrees) and (b) with different infill percentages (in \%).

\subsection{Influence of Infill Percentage}

Baich et al. [93] studied the effects of infill percentage on mechanical strength and print costs for $3 \mathrm{D}$ printed ABS parts produced using infill percentages of $50 \%, 75 \%$, and $100 \%$. They found that samples produced with $100 \%$ infill outperform samples produced with $50 \%$ infills for all mechanical properties, as shown in Figure 8a,b. Yadav et al. [94] showed that UTS increases by $20 \%$ when the infill percentage increases from $20 \%$ to $60 \%$. Samykano et al. [95] studied the influence of printing parameters, including infill percentage, on the mechanical properties of FDM printed ABS and proposed a mathematical model that predicts the properties numerically through response surface methodology. The results showed that tensile strength and Young's modulus improve significantly as the infill percentage increases. Furthermore, a study by Panes et al. [81] concluded that increasing the infill percentage from $20 \%$ to $50 \%$ for ABS improves its UTS by $26 \%$, yield stress by $24 \%$, Young's modulus by $45 \%$ and elongation at break by $1 \%$. 

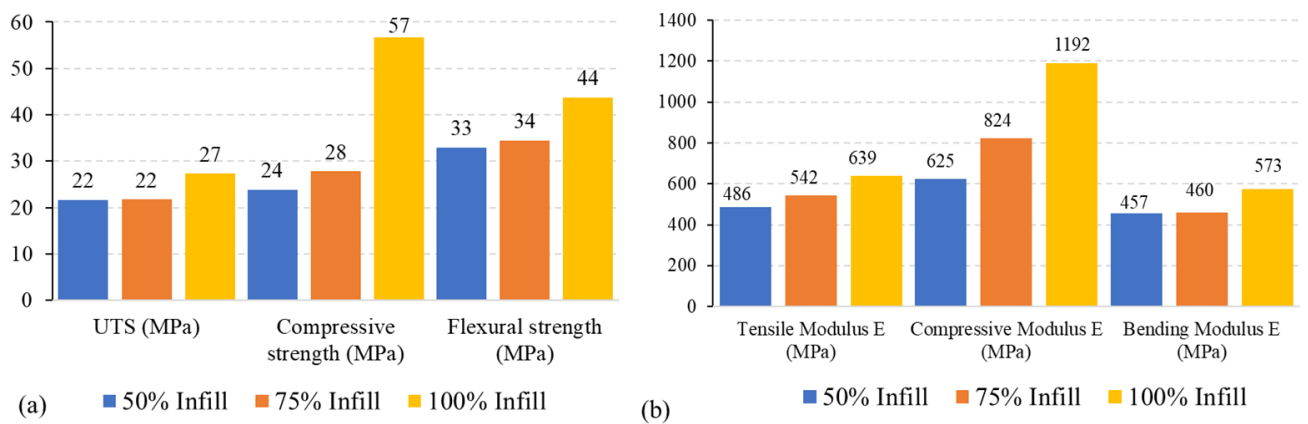

Figure 8. Effects of different infill percentages on various characteristics of ABS in $(\mathbf{a}, \mathbf{b})$.

\subsection{Influence of Printing Speed}

A study in [96] investigated the effect of printing speed on ABS tensile strength with different layer thicknesses $(0.1$ and $0.3 \mathrm{~mm})$ and extruder temperatures $\left(230^{\circ} \mathrm{C}\right.$ and $\left.270{ }^{\circ} \mathrm{C}\right)$. The study concluded that increasing printing speed negatively affects tensile strength for all layer thicknesses and extruder temperatures. Typically, when printing speed is increased, the extrusion width decreases. This effect causes a reduction of material deposition and micro-voids inside the printed part which weakens it. Another study in [50] examined the effects of three different printing speeds $(30,35$, and $40 \mathrm{~mm} / \mathrm{s})$ on tensile strength. The study arrived at similar results: the tensile strength dropped from $15.5 \mathrm{MPa}$ to $13.7 \mathrm{MPa}$. Additionally, a study in [97] studied ABS rotating flexural fatigue performance's sensitivity to printing speed $(25,30,35 \mathrm{~mm} / \mathrm{s})$. The study concluded that different printing speeds and infill percentages have a moderate effect on the fatigue cycles to failure of ABS (Figure 9a,b). However, the study revealed that infill patterns have a more significant influence than does printing speed on the fatigue life of ABS.
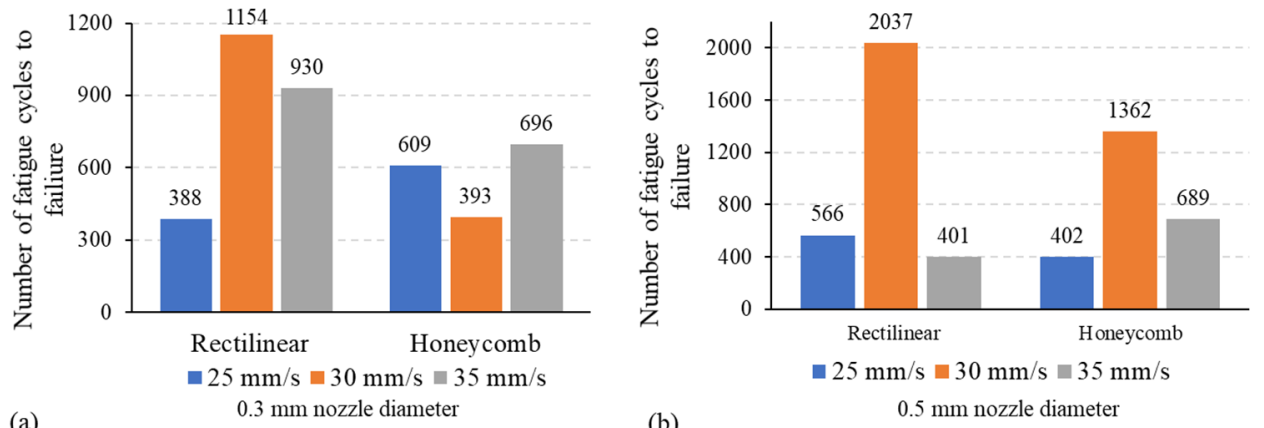

Figure 9. ABS fatigue life to failure sensitivity to printing speed with different infill patterns and nozzle diameters of (a) $0.3 \mathrm{~mm}$ and (b) $0.5 \mathrm{~mm}$.

\subsection{ABS Mechanical Properties Sensitivity Study Using ANOVA}

The range for each process parameter is summarized in Table 4 . Figure 10 shows that Young's modulus is significantly affected by infill percentage and layer thickness. UTS is mainly affected by infill percentage and raster angle. Additionally, flexural strength is greatly affected by infill percentage and printing speed. Elongation at break is determined by infill percentage and raster angle. The process parameters are ranked in Table 5 according to their influence on the specified ABS mechanical properties. 
Table 4. Process parameters range used for ABS along with the related settings.

\begin{tabular}{ccccc}
\hline Process Parameter & Range Selected & Low & Middle & High \\
\hline Raster angle & $0^{\circ}-90^{\circ}$ & $0^{\circ}$ & $45^{\circ}$ & $90^{\circ}$ \\
Layer thickness & $0.1-0.3 \mathrm{~mm}$ & $0.1 \mathrm{~mm}$ & $0.2 \mathrm{~mm}$ & $0.3 \mathrm{~mm}$ \\
Infill percentage & $60-100 \%$ & $60 \%$ & $80 \%$ & $100 \%$ \\
Printing speed & $20-40 \mathrm{~mm} / \mathrm{s}$ & $20 \mathrm{~mm} / \mathrm{s}$ & $30 \mathrm{~mm} / \mathrm{s}$ & $40 \mathrm{~mm} / \mathrm{s}$ \\
\hline
\end{tabular}

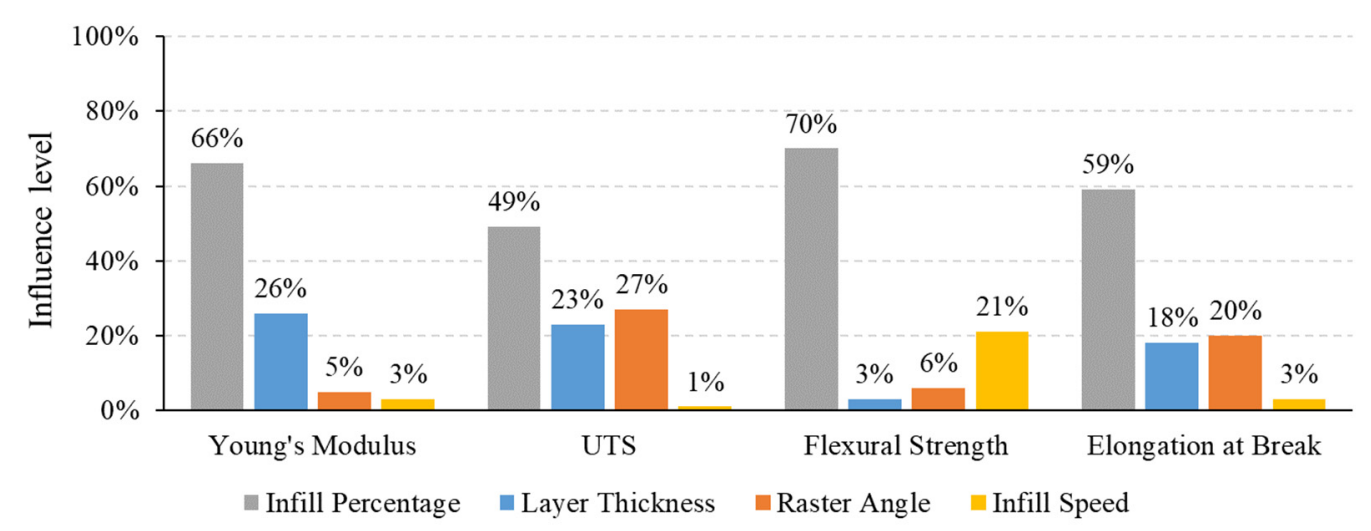

Figure 10. Process parameter's relative influence on ABS mechanical properties.

Table 5. Table ranking parameters according to influence on ABS mechanical properties as determined by ANOVA.

\begin{tabular}{|c|c|c|c|c|}
\hline Material Property & First & Second & Third & Fourth \\
\hline Young's Modulus & Infill Percentage & $\begin{array}{c}\text { Layer } \\
\text { Thickness }\end{array}$ & Raster Angle & Printing speed \\
\hline UTS & Infill Percentage & $\begin{array}{l}\text { Layer } \\
\text { Thickness }\end{array}$ & Raster Angle & Printing speed \\
\hline Flexural Strength & Infill Percentage & Printing speed & Raster Angle & Layer Thickness \\
\hline $\begin{array}{c}\text { Elongation at } \\
\text { break }\end{array}$ & Infill Percentage & Raster Angle & Layer Thickness & Printing speed \\
\hline
\end{tabular}

\section{Polyether Ether Ketone (PEEK)}

PEEK is a thermoplastic biomaterial that has superior thermal resistance, good dimensional stability, superior creep resistance, and excellent mechanical properties. It is used in compressor seals, aerospace components, and bearings as well as to support bone healing in human bodies [98].

\subsection{Influence of Raster Angle}

Wu et al. [15] investigated the effects of various raster angles on the mechanical characteristics of 3D fabricated PEEK parts. The study concluded that raster angle would affect the mechanical behavior of PEEK parts, as illustrated in Figure 11.

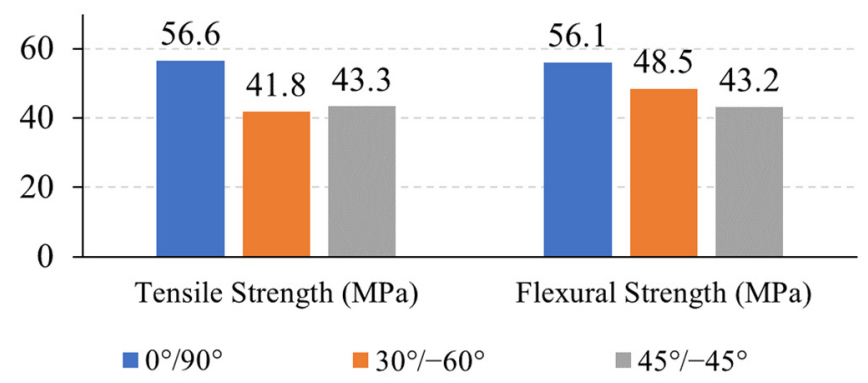

Figure 11. PEEK strength sensitivity to various raster angles (in degrees). 


\subsection{Influence of Layer Thickness}

Layer thickness effects on the mechanical characteristics of PEEK fabricated parts is significant. A research in [15] demonstrated the influence of different layer thicknesses on PEEK part's mechanical properties. The variance of layer thickness has a major influence on tensile strength, yet it has a minor influence on compressive and flexural strength. The results are shown in Figure 12a. Another study in [55] studied the effects of different layer thicknesses with different nozzle diameters $(0.6$ and $0.8 \mathrm{~mm})$. Layer thickness variation in the range of $(0.25-0.4 \mathrm{~mm})$ has decreased the part's tensile strength significantly by $34 \%$ at a nozzle diameter of $0.6 \mathrm{~mm}$. However, changing the layer thickness from 0.35 to $0.5 \mathrm{~mm}$ results in a smaller change in tensile strength when the nozzle diameter is $0.8 \mathrm{~mm}$. This is presented in Figure 12b. More studies in $[56,99]$ investigated the influence of different layer thicknesses on PEEK's tensile strength, elongation and Young's modulus. The results are shown in Figure 13a-c.

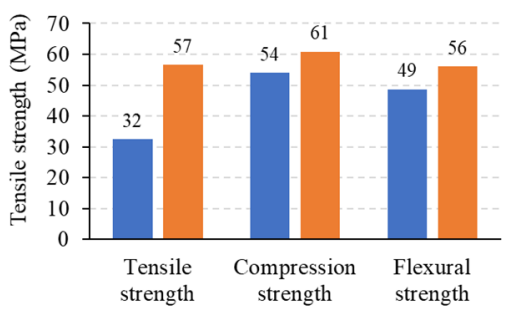

(a)

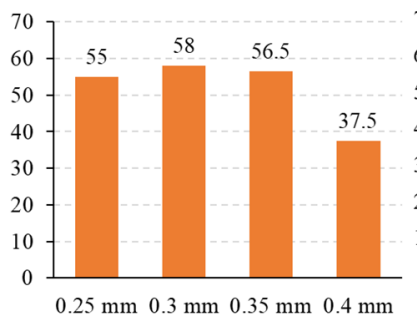

(b)

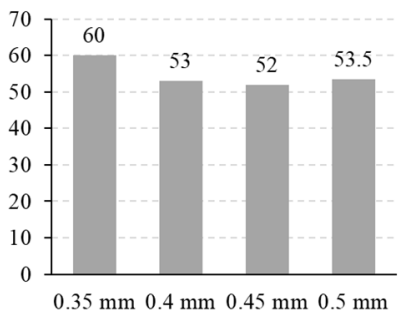

Nozzle $\emptyset 0.8 \mathrm{~mm}$

Figure 12. (a) PEEK tensile, compression and flexural strength sensitivity to layer thickness and (b) with different nozzle diameters (in $\mathrm{mm}$ ).
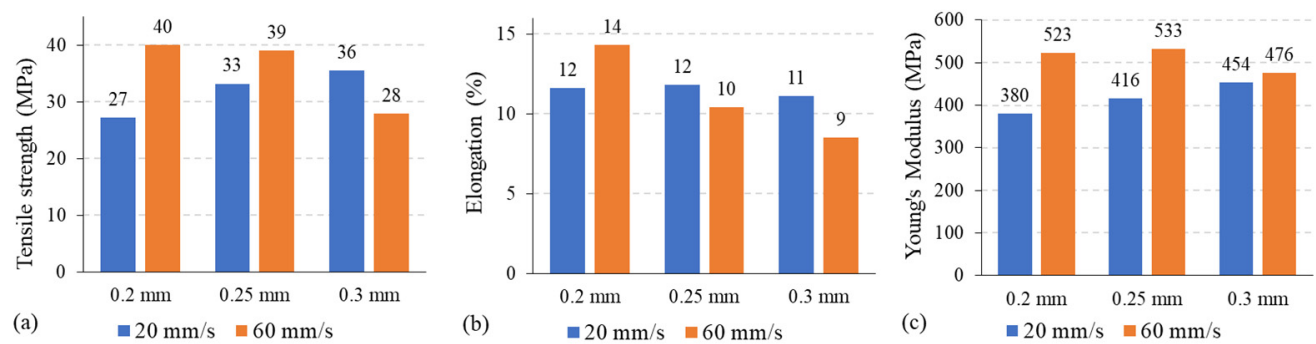

Figure 13. PEEK (a) strength, (b) elongation at break, (c) Young's modulus and sensitivity to various layer thicknesses with different printing speeds (in $\mathrm{mm} / \mathrm{s}$ ).

\subsection{Influence of Infill Percentage}

Rinaldi et al. [100] studied PEEK parts produced via FDM. They concluded that the infill percentage is significant. They demonstrated that mechanical performance decreases with infill percentages less than $100 \%$. The UTS was $60 \mathrm{MPa}$ with an infill percentage of $20 \%, 69 \mathrm{MPa}$ with $50 \%$, and $99 \mathrm{MPa}$ with $100 \%$. Young's modulus was $2.3 \mathrm{GPa}$ with $20 \%$, $2.3 \mathrm{GPa}$ with $50 \%$, and $4.0 \mathrm{GPa}$ with $100 \%$.

\subsection{Influence of Printing Speed}

A study in [55] shows that PEEK printed part's mechanical properties, strength, and surface quality can be improved by optimizing printing parameters. One of these parameters is printing speed, which can improve the performance of PEEK parts. The research studied the influence of four different printing speeds $(17,20,23$, and $26 \mathrm{~mm} / \mathrm{s})$ with different layer thicknesses on tensile strength. The results show that increasing printing speeds lead to decreased extrusion width (a reduction of material deposition) which weakens the PEEK printed parts regardless of the layer thickness. Another study in [101] presented the effects of printing speeds $(5,10,15 \mathrm{~mm} / \mathrm{s})$ on PEEK biomedical parts, as shown in Figure 14a,b. The study concluded that the optimal printing parameters 
depend on the shape and function of the part. Additionally, a study in [102] examined how compression and shear strength varied with different printing speeds ( 25 and $33 \mathrm{~mm} / \mathrm{s}$ ). The results show minor effects on both compression ( $3 \%$ reduction) and shear strength $(7 \%$ reduction).

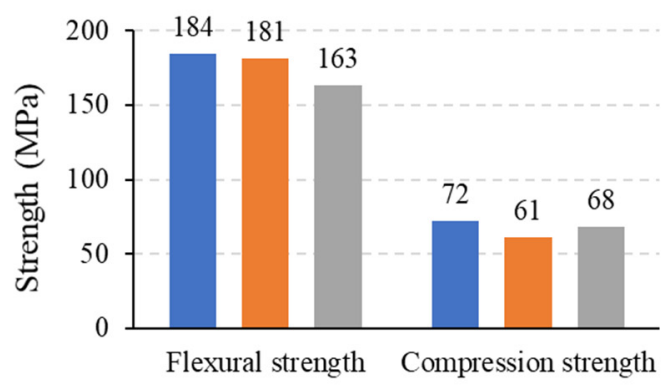

(a)

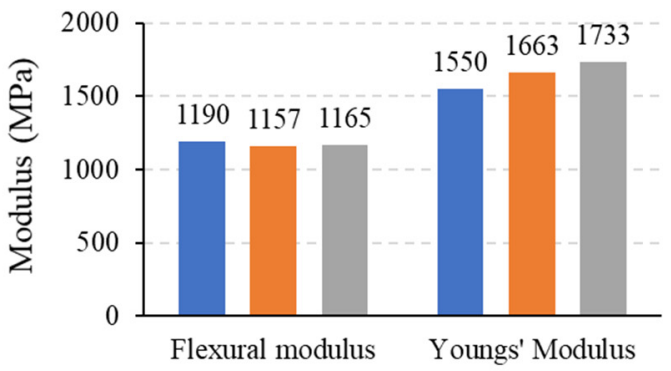

(b)
$-5 \mathrm{~mm} / \mathrm{s}=10 \mathrm{~mm} / \mathrm{s}=15 \mathrm{~mm} / \mathrm{s}$

Figure 14. PEEK (a) strength and (b) modulus sensitivity to printing speeds.

\subsection{PEEK Mechanical Properties Sensitivity Study Using ANOVA}

The range for each process parameter is summarized in Table 6. Figure 15 shows that Young's modulus is significantly affected by infill percentage. UTS is mainly affected by infill percentage. Additionally, flexural strength is greatly affected by raster angle and printing speed. Elongation at break is determined by infill percentage and raster angle. The process parameters are ranked in Table 7 according to their influence on the specified PEEK mechanical properties.

Table 6. Process parameters range used for PEEK material along with the related settings.

\begin{tabular}{ccccc}
\hline Process Parameter & Range Selected & Low & Middle & High \\
\hline Raster angle & $0^{\circ}-90^{\circ}$ & $0^{\circ}$ & $45^{\circ}$ & $90^{\circ}$ \\
Layer thickness & $0.07-0.21 \mathrm{~mm}$ & $0.07 \mathrm{~mm}$ & $0.14 \mathrm{~mm}$ & $0.21 \mathrm{~mm}$ \\
Infill percentage & $20-100 \%$ & $20 \%$ & $50 \%$ & $100 \%$ \\
Printing speed & $10-30 \mathrm{~mm} / \mathrm{s}$ & $10 \mathrm{~mm} / \mathrm{s}$ & $20 \mathrm{~mm} / \mathrm{s}$ & $30 \mathrm{~mm} / \mathrm{s}$ \\
\hline
\end{tabular}

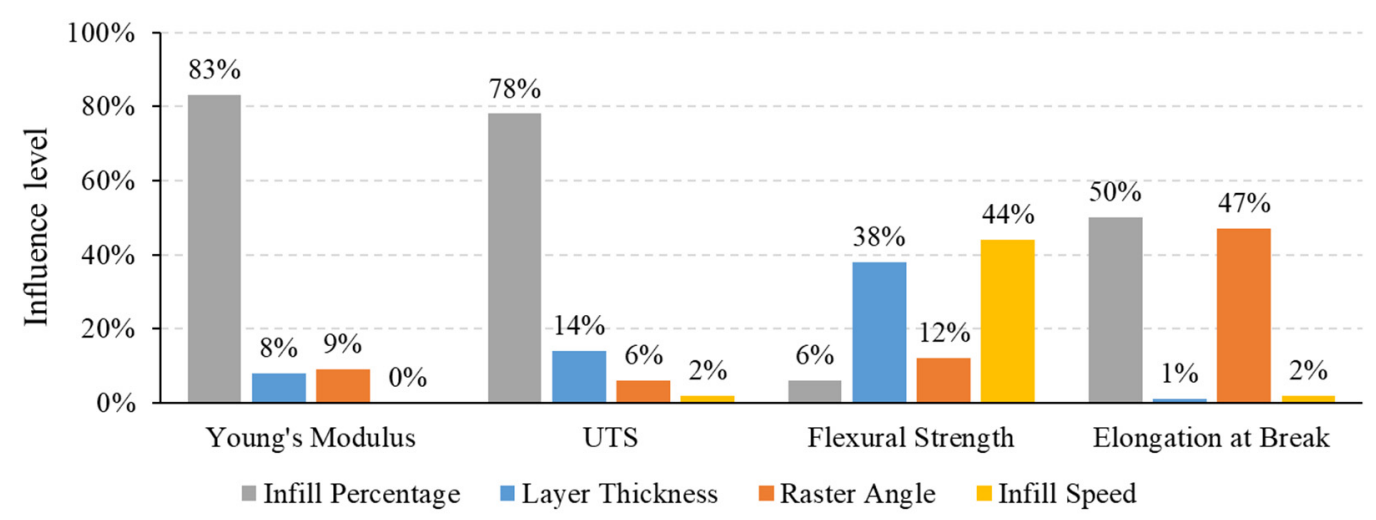

Figure 15. Process parameter's relative influence on PEEK mechanical properties. 
Table 7. Table ranking parameters according to influence on PEEK mechanical properties as determined by ANOVA.

\begin{tabular}{|c|c|c|c|c|}
\hline Material Property & First & Second & Third & Fourth \\
\hline Young's Modulus & $\begin{array}{c}\text { Infill } \\
\text { Percentage }\end{array}$ & Raster Angle & Layer Thickness & Printing speed \\
\hline UTS & $\begin{array}{c}\text { Infill } \\
\text { Percentage }\end{array}$ & Layer Thickness & Raster Angle & Printing speed \\
\hline Flexural Strength & Printing speed & Layer Thickness & Raster Angle & Infill Percentage \\
\hline $\begin{array}{c}\text { Elongation at } \\
\text { break }\end{array}$ & $\begin{array}{c}\text { Infill } \\
\text { Percentage }\end{array}$ & Raster Angle & Printing speed & Layer Thickness \\
\hline
\end{tabular}

\section{Polyethylene Terephthalate Glycol (PETG)}

PETG is a derivative polymer of the polyethylene terephthalate family. It is familiar in traditional manufacturing processes (e.g., injection molding) and was recently introduced in AM. Its promising properties and capabilities are being researched. It has excellent properties such as formability, thermal variations, and a low forming temperature. It is used in medical implants and many commercial applications such as packaging materials [103].

\subsection{Influence of Raster Angle}

PETG material outperforms ABS and PLA for some applications due to its strength and stability under many loading conditions involving fatigue and fracture [104]. Dolzyk et al. [105] investigated the mechanical properties of 3D printed PETG parts by conducting coupon tests with four raster angles: longitudinal $\left(0^{\circ}\right)$, transversal $\left(90^{\circ}\right)$, diagonal $\left(45^{\circ}\right)$, and crisscross $\left(45^{\circ} /-45^{\circ}\right)$. Figure 16a,b show the effects of raster angle on PETG mechanical properties. The two specimens' highest and lowest UTS were $45.7 \mathrm{MPa}$ and 41.6 $\mathrm{MPa}$, which correspond to longitudinal and diagonal raster orientations. Furthermore, the two specimens' highest and lowest Young's modulus are 1.62 GPa and 1.48 GPa, which correspond to longitudinal and crisscross raster orientations, respectively.
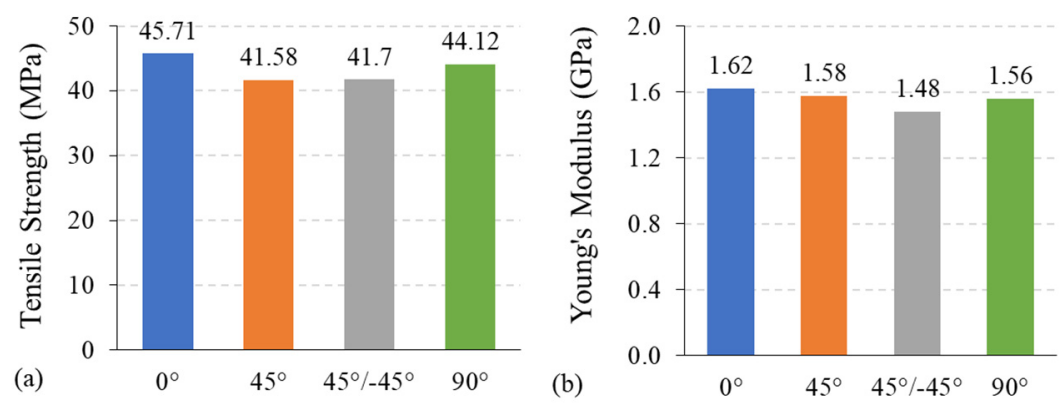

Figure 16. PEEK (a) strength and (b) Young's modulus sensitivity to various raster angles (in degrees).

\subsection{Influence of Layer Thickness}

PETG's mechanical properties vary significantly as layer thickness changes. A study in [106] shows that layer thickness affects tensile and flexural strength. The study investigated the influence of different layer thicknesses $(0.17,0.23$, and $0.3 \mathrm{~mm})$ with different feed speeds. The results are presented in Figure 17a,b. A study in [107] investigated the influence of layer thickness on PETG tensile strength. The results show that UTS decreased by $30 \%$ as the layer thickness changed from 0.1 to $0.2 \mathrm{~mm}$. A recent study in [62] stated that tensile strength and Young's modulus are heavily affected by layer thickness. The highest tensile strength is attained at the smallest layer thickness (Figure 18a,b). 

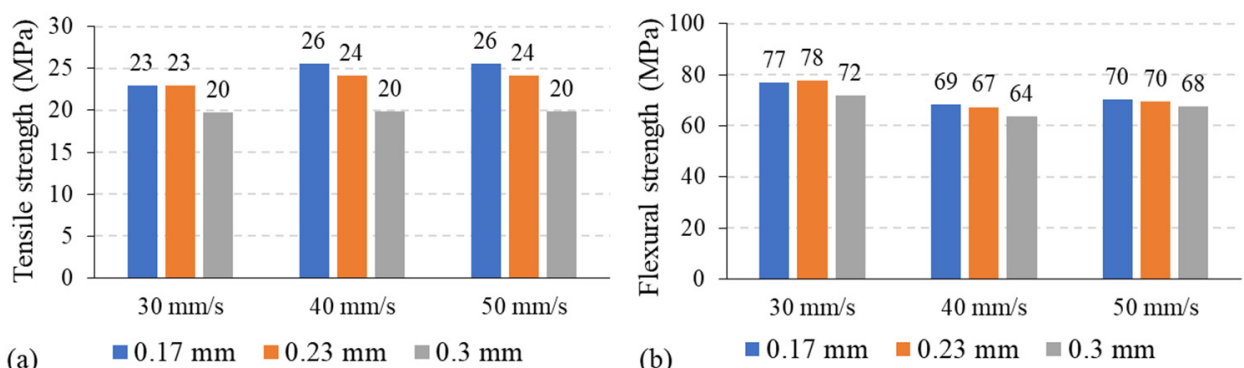

(a)

$=0.17 \mathrm{~mm} \quad \square 0.23 \mathrm{~mm} \quad \square 0.3 \mathrm{~mm}$

(b)

$\square 0.17 \mathrm{~mm} \quad 0.23 \mathrm{~mm} \quad \square 0.3 \mathrm{~mm}$

Figure 17. PETG (a) tensile and (b) flexural strength sensitivity to various layer thicknesses with different printing speeds (in $\mathrm{mm} / \mathrm{s}$ ).
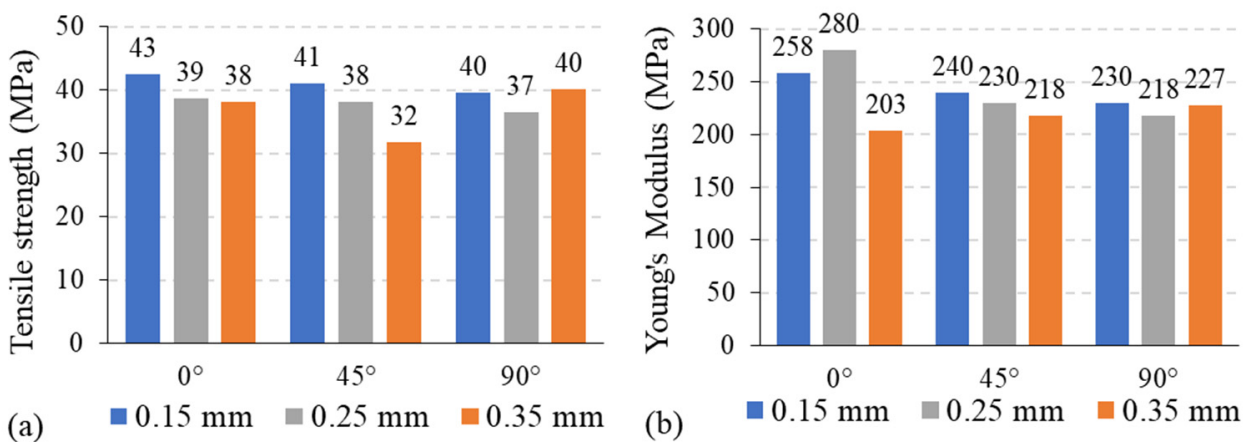

Figure 18. PETG (a) tensile strength and (b) Young's modulus sensitivity to layer thickness with different raster angles (in degrees).

\subsection{Influence of Infill Percentage}

Srinivasan et al. [60] studied the effects of infill percentage on the mechanical properties of PETG parts fabricated via FDM with fixed layer thickness. The study concluded that decreasing the infill percentage from $100 \%$ to $20 \%$ decreased the UTS from $32.1 \mathrm{MPa}$ to $17.4 \mathrm{MPa}\left(45 \%\right.$ drop) and increased the surface roughness $\left(\mathrm{R}_{\mathrm{a}}\right)$ from $2.8 \mu \mathrm{m}$ to $3.8 \mu \mathrm{m}$. Increasing the infill percentage to $100 \%$ led to smoother surfaces. Another study by Srinivasan et al. [107] investigated the influence of FDM parameters by varying layer thickness, infill percentage, and infill pattern. They concluded that the UTS increases with increasing infill percentage (Figure 19a). On the other hand, increasing infill percentage decreased the surface roughness (Figure 19b).
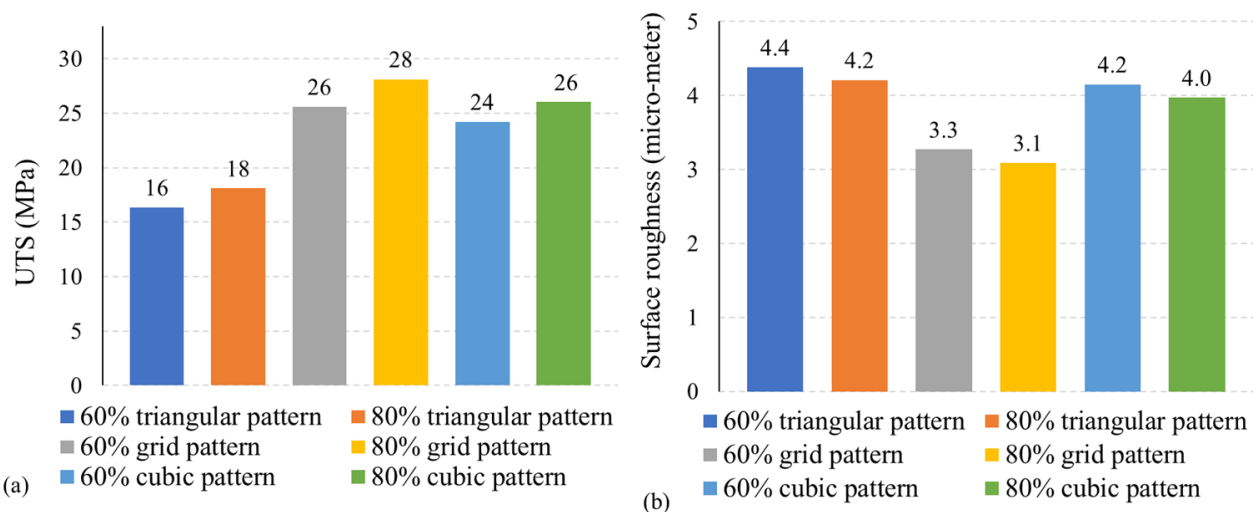

Figure 19. Effects of infill percentage with different pattern shapes on (a) UTS and (b) surface roughness. 


\subsection{Influence of Printing Speed}

A study in [108] studied the effects of printing speed on the hardness, tensile strength, and flexural strength of PETG. It presented a relationship form to optimize mechanical properties. The results show that increasing printing speed slightly decreases tensile and flexural strength but slightly increases hardness (in BHN). A study in [106] shows that printing speed affected the tensile and flexural strength. The study investigated the influence of printing speed with different layer thicknesses $(0.17,0.23$, and $0.3 \mathrm{~mm})$. The study arrived at similar results to those of [108]; tensile and flexural strength decrease as printing speed increases regardless of layer thicknesses. Additionally, a study in [62] stated that tensile strength and Young's modulus are barely affected by printing speed. The highest strengths were attained at the lowest printing speed (Figure 20a,b). This is mainly due to high printing speeds not allowing sufficient time for filament adhesion in previous layers especially for small parts.
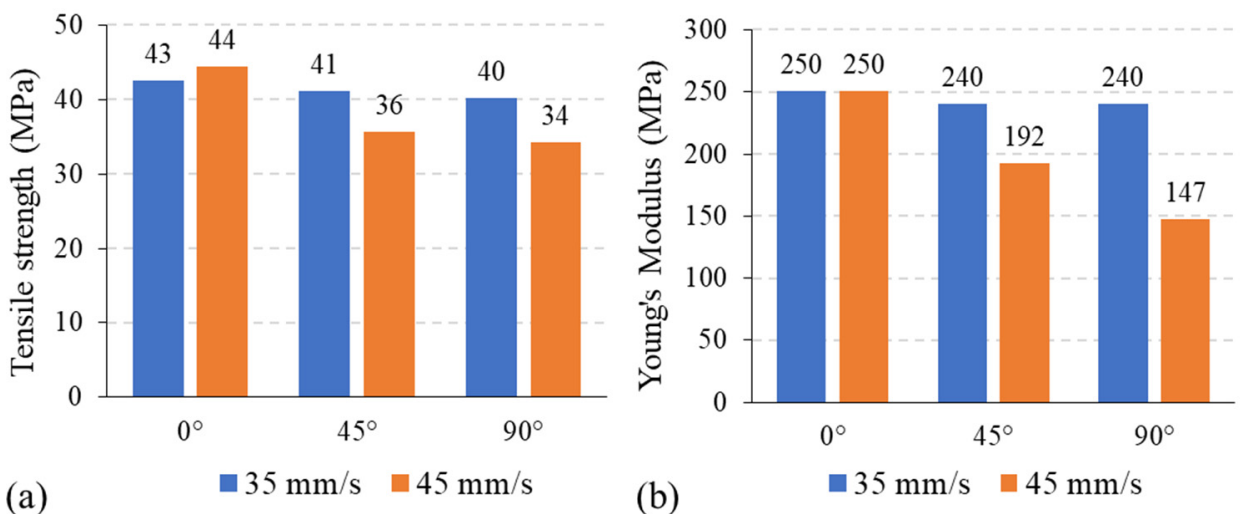

Figure 20. PETG (a) strength and (b) Young's modulus sensitivity to printing speeds with different raster angles (in degrees).

\subsection{PETG Mechanical Properties Sensitivity Study Using ANOVA}

The range for each process parameter is summarized in Table 8 . Figure 21 shows that Young's modulus is significantly affected by infill percentage. UTS is mainly affected by infill percentage and layer thickness. Additionally, flexural strength is greatly affected by printing speed and layer thickness. Elongation at break is determined by raster angle and infill percentage. The process parameters are ranked in Table 9 according to their influence on the specified PETG mechanical properties.

Table 8. Process parameters range used for PETG material along with the related settings.

\begin{tabular}{ccccc}
\hline Process Parameter & Range Selected & Low & Middle & High \\
\hline Raster angle & $0^{\circ}-90^{\circ}$ & $0^{\circ}$ & $45^{\circ}$ & $90^{\circ}$ \\
Layer thickness & $0.2-0.4 \mathrm{~mm}$ & $0.2 \mathrm{~mm}$ & $0.3 \mathrm{~mm}$ & $0.4 \mathrm{~mm}$ \\
Infill percentage & $50-100 \%$ & $50 \%$ & $75 \%$ & $100 \%$ \\
Printing speed & $15-35 \mathrm{~mm} / \mathrm{s}$ & $15 \mathrm{~mm} / \mathrm{s}$ & $25 \mathrm{~mm} / \mathrm{s}$ & $35 \mathrm{~mm} / \mathrm{s}$ \\
\hline
\end{tabular}




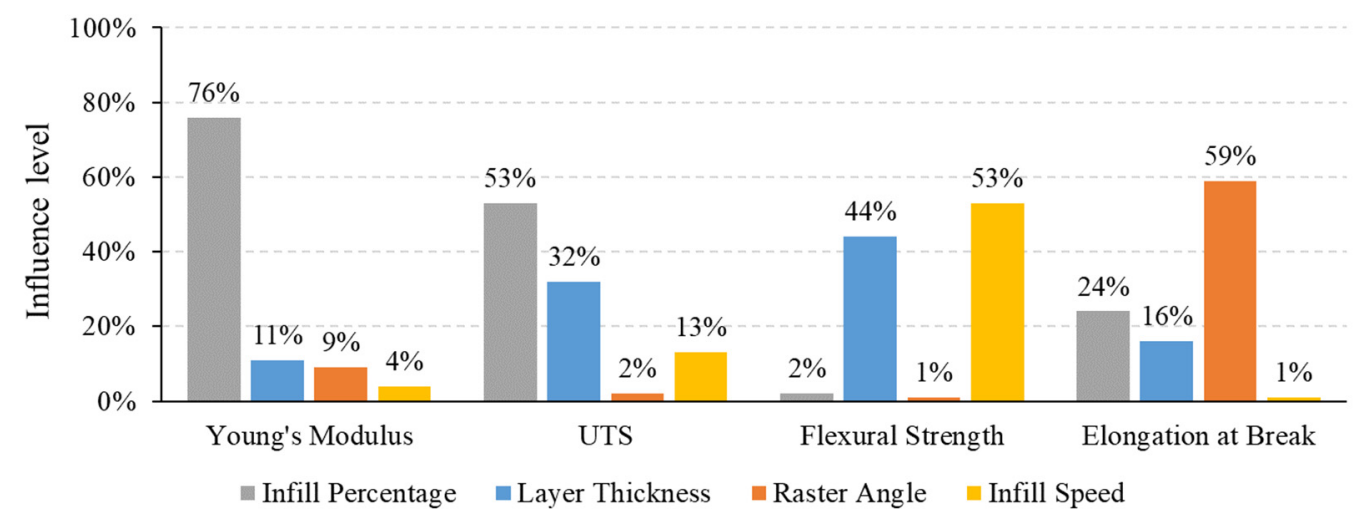

Figure 21. Process parameter's relative influence on PETG mechanical properties.

Table 9. Table ranking parameters according to influence on PETG mechanical properties as determined by ANOVA.

\begin{tabular}{|c|c|c|c|c|}
\hline Material Property & First & Second & Third & Fourth \\
\hline Young's Modulus & Infill percentage & Layer thickness & Raster angle & Printing speed \\
\hline UTS & Infill percentage & Layer thickness & Printing speed & Raster angle \\
\hline Flexural Strength & Printing speed & Layer thickness & $\begin{array}{c}\text { Infill } \\
\text { percentage }\end{array}$ & Raster angle \\
\hline $\begin{array}{c}\text { Elongation at } \\
\text { break }\end{array}$ & Raster angle & Infill percentage & $\begin{array}{l}\text { Layer } \\
\text { thickness }\end{array}$ & Printing speed \\
\hline
\end{tabular}

\section{Conclusions}

This research presented a comparative evaluation of FDM process parameters that influence the mechanical properties of parts made of PLA, ABS, PEEK, and PETG. ANOVA was used to evaluate the effects of four process parameters (raster angle, layer thickness, infill percentage, and printing speed) on mechanical properties. The influence of each process parameter was quantified and ranked based on ascending variance values obtained by ANOVA. The study's conclusions are as follows:

- Infill percentage is the most influential process parameter on all the material's mechanical properties.

- Infill percentage had the most significant influence on PLA and ABS mechanical behaviors.

- The Young's modulus and UTS of PEEK were found to be affected mainly by infill percentage. Flexural strength and fractural strain were significantly affected by printing speed and infill percentage, respectively.

- The Young's modulus and UTS of PETG were affected mainly by infill percentage. Additionally, printing speed mainly affected flexural strength, and raster angle greatly influenced elongation at break.

- The outcomes of this study demonstrate that the material's mechanical properties depend greatly on the process parameters selected. It was difficult to conduct a study with fixed process ranges, as other FDM parameters (such as raster width, shell thickness, infill pattern, and nozzle temperature) were not constant yet in similar ranges, due to the lack of data in the literature. This study was based on data available in the literature, and different studies used different process ranges for each material. Therefore, it is recommended that a similar study be conducted with a fixed set of process parameter ranges for all materials (PLA, ABS, PEEK, and PETG) to further investigate the influence of process parameters on mechanical properties. 
Author Contributions: Conceptualization, M.A. and S.G.; Methodology, M.A. and S.G.; Software, S.G.; Validation, M.A. and S.G.; Formal analysis, M.A. and S.G.; Investigation, M.A. and S.G.; Resources, M.A. and S.G.; Writing—original draft preparation, M.A. and S.G.; Writing-review and editing, M.A. and S.G.; Visualization, M.A. and S.G.; Project administration, M.A. Both authors have read and agreed to the published version of the manuscript.

Funding: This research received no external funding.

Data Availability Statement: Data sharing available upon request.

Acknowledgments: We would like to thank Mohammed Aman from the Industrial Engineering Department, Faculty of Engineering in Rabigh who helped us in concluding the ANOVA results within the limited time frame.

Conflicts of Interest: The authors declare no conflict of interest.

\section{References}

1. Ngo, T.D.; Kashani, A.; Imbalzano, G.; Nguyen, K.T.; Hui, D. Additive manufacturing (3D printing): A review of materials, methods, applications and challenges. Compos. Part B Eng. 2018, 143, 172-196. [CrossRef]

2. Korpela, J.; Kokkari, A.; Korhonen, H.; Malin, M.; Närhi, T.; Seppälä, J. Biodegradable and bioactive porous scaffold structures prepared using fused deposition modeling. J. Biomed. Mater. Res. Part B Appl. Biomater. 2013, 101, 610-619. [CrossRef]

3. Duda, T.; Raghavan, L.V. 3D metal printing technology: The need to re-invent design practice. AI Soc. 2018, 33, 241-252. [CrossRef]

4. Popescu, D.; Zapciu, A.; Amza, C.; Baciu, F.; Marinescu, R. FDM process parameters influence over the mechanical properties of polymer specimens: A review. Polym. Test. 2018, 69, 157-166. [CrossRef]

5. Garcia, E.A.; Ayranci, C.; Qureshi, A.J. Material property-manufacturing process optimization for form 2 vat-photo polymerization 3D Printers. J. Manuf. Mater. Process. 2020, 4, 12. [CrossRef]

6. Raney, K.; Lani, E.; Kalla, D.K. Experimental characterization of the tensile strength of ABS parts manufactured by fused deposition modeling process. Mater. Today Proc. 2017, 4, 7956-7961. [CrossRef]

7. Nancharaiah, T.; Raju, D.R.; Raju, V.R. An experimental investigation on surface quality and dimensional accuracy of FDM components. Int. J. Emerg. Technol. 2010, 1, 106-111.

8. Nidagundi, V.B.; Keshavamurthy, R.; Prakash, C. Studies on Parametric Optimization for Fused Deposition Modelling Process. Mater. Today Proc. 2015, 2, 1691-1699. [CrossRef]

9. Durgun, I.; Ertan, R. Experimental investigation of FDM process for improvement of mechanical properties and production cost. Rapid Prototyp. J. 2014, 20, 228-235. [CrossRef]

10. Letcher, T.; Rankouhi, B.; Javadpour, S. Experimental Study of Mechanical Properties of Additively Manufactured ABS Plastic as a Function of Layer Parameters. In Proceedings of the ASME 2015 International Mechanical Engineering Congress and Exposition (IMECE), Houston, TX, USA, 13-19 November 2015; American Society of Mechanical Engineers Digital Collection: Houston, TX, USA, 2015.

11. Krajangsawasdi, N.; Blok, L.G.; Hamerton, I.; Longana, M.L.; Woods, B.K.S.; Ivanov, D.S. Fused deposition modelling of fibre reinforced polymer composites: A parametric review. J. Compos. Sci. 2021, 5, 29. [CrossRef]

12. Nancharaiah, T. Optimization of process parameters in FDM process using design of experiments. Int. J. Emerg. Technol. 2011, 2, 100-102.

13. Sood, A.K.; Ohdar, R.K.; Mahapatra, S.S. Experimental investigation and empirical modelling of FDM process for compressive strength improvement. Int. J. Adv. Res. 2012, 3, 81-90. [CrossRef]

14. Sood, A.K.; Ohdar, R.; Mahapatra, S.S. Parametric appraisal of mechanical property of fused deposition modelling processed parts. Mater. Des. 2010, 31, 287-295. [CrossRef]

15. Wu, W.; Geng, P.; Li, G.; Zhao, D.; Zhang, H.; Zhao, J. Influence of Layer Thickness and Raster Angle on the Mechanical Properties of 3D-Printed PEEK and a Comparative Mechanical Study between PEEK and ABS. Materials 2015, 8, 5834-5846. [CrossRef]

16. Lee, B.H.; Abdullah, J.; Khan, Z.A. Optimization of rapid prototyping parameters for production of flexible ABS object. J. Mater. Process. Technol. 2005, 169, 54-61. [CrossRef]

17. Sun, Q.; Rizvi, G.; Bellehumeur, C.; Gu, P. Effect of processing conditions on the bonding quality of FDM polymer filaments. Rapid Prototyp. J. 2008, 14, 72-80. [CrossRef]

18. Ahn, S.H.; Montero, M.; Odell, D.; Roundy, S.; Wright, P.K. Anisotropic material properties of fused deposition modeling ABS. Rapid Prototyp. J. 2002, 8, 248-257. [CrossRef]

19. Bakar, N.S.A.; Alkahari, M.R.; Boejang, H. Analysis on fused deposition modelling performance. J. Zhejiang Univ. Sci. A 2010, 11, 972-977. [CrossRef]

20. Rajpurohit, S.; Dave, H.K. Analysis of tensile strength of a fused filament fabricated PLA part using an open-source 3D printer. Int. J. Adv. Manuf. Technol. 2019, 101, 1525-1536. [CrossRef]

21. Srinivasan, R.; Pridhar, T.; Ramprasath, L.; Charan, N.S.; Ruban, W. Prediction of tensile strength in FDM printed ABS parts using response surface methodology (RSM). Mater. Today Proc. 2020, 27, 1827-1832. [CrossRef] 
22. Bellini, A.; Güçeri, S. Mechanical characterization of parts fabricated using fused deposition modeling. Rapid Prototyp. J. 2003, 9, 252-264. [CrossRef]

23. Ang, K.C.; Leong, K.F.; Chua, C.K.; Chandrasekaran, M. Investigation of the mechanical properties and porosity relationships in fused deposition modelling-fabricated porous structures. Rapid Prototyp. J. 2006, 12, 100-105. [CrossRef]

24. Chang, D.-Y.; Huang, B.-H. Studies on profile error and extruding aperture for the RP parts using the fused deposition modeling process. Int. J. Adv. Manuf. Technol. 2011, 53, 1027-1037. [CrossRef]

25. Croccolo, D.; De Agostinis, M.; Olmi, G. Experimental characterization and analytical modelling of the mechanical behaviour of fused deposition processed parts made of ABS-M30. Comput. Mater. Sci. 2013, 79, 506-518. [CrossRef]

26. Magalhães, L.; Volpato, N.; Luersen, M. Evaluation of stiffness and strength in fused deposition sandwich specimens. J. Braz. Soc. Mech. Sci. Eng. 2014, 36, 449-459. [CrossRef]

27. Carneiro, O.S.; Silva, A.; Gomes, R. Fused deposition modeling with polypropylene. Mater. Des. 2015, 83, 768-776. [CrossRef]

28. Cantrell, J.T.; Rohde, S.; Damiani, D.; Gurnani, R.; DiSandro, L.; Anton, J.; Young, A.; Jerez, A.; Steinbach, D.; Kroese, C.; et al. Experimental characterization of the mechanical properties of 3D-printed ABS and polycarbonate parts. Rapid Prototyp. J. 2017, 23, 811-824. [CrossRef]

29. Arif, M.; Kumar, S.; Varadarajan, K.; Cantwell, W. Performance of biocompatible PEEK processed by fused deposition additive manufacturing. Mater. Des. 2018, 146, 249-259. [CrossRef]

30. Gebisa, A.W.; Lemu, H.G. Investigating effects of Fused-Deposition Modeling (FDM) processing parameters on flexural properties of ULTEM 9085 using designed experiment. Materials 2018, 11, 500. [CrossRef]

31. Rayegani, F.; Onwubolu, G.C. Fused deposition modelling (FDM) process parameter prediction and optimization using group method for data handling (GMDH) and differential evolution (DE). Int. J. Adv. Manuf. Technol. 2014, 73, 509-519. [CrossRef]

32. Qattawi, A.; Alrawi, B.; Guzman, A. Experimental optimization of fused deposition modelling processing parameters: A design-for-manufacturing approach. Procedia Manuf. 2017, 10, 791-803. [CrossRef]

33. Panda, S.K.; Padhee, S.; Sood, A.K.; Mahapatra, S.S. Optimization of Fused Deposition Modelling (FDM) Process Parameters Using Bacterial Foraging Technique. Intell. Inf. Manag. 2009, 1, 89-97. [CrossRef]

34. Akande, S.O. Dimensional Accuracy and Surface Finish Optimization of Fused Deposition Modelling Parts using Desirability Function Analysis. Int. J. Eng. Res. Technol. 2015, 4, 196-202. [CrossRef]

35. Gurrala, P.K.; Regalla, S.P. Multi-objective optimisation of strength and volumetric shrinkage of FDM parts: A multi-objective optimization scheme is used to optimize the strength and volumetric shrinkage of FDM parts considering different process parameters. Virtual Phys. Prototyp. 2014, 9, 127-138. [CrossRef]

36. Rao, R.V.; Rai, D.P. Optimization of fused deposition modeling process using teaching-learning-based optimization algorithm. Eng. Sci. Technol. Int. J. 2016, 19, 587-603. [CrossRef]

37. Algarni, M. The Influence of Raster Angle and Moisture Content on the Mechanical Properties of PLA Parts Produced by Fused Deposition Modeling. Polymers 2021, 13, 237. [CrossRef] [PubMed]

38. Kiendl, J.; Gao, C. Controlling toughness and strength of FDM 3D-printed PLA components through the raster layup. Compos. Part B Eng. 2020, 180, 107562. [CrossRef]

39. Rajpurohit, S.R.; Dave, H.K. Impact strength of 3D printed PLA using open source FFF-based 3D printer. Prog. Addit. Manuf. 2021, 6, 119-131. [CrossRef]

40. Sukanto, H.; Smaradhana, D.F.; Triyono, J.; Wicaksono, P. Investigating the Effect of Layer Thickness on the Product Quality of PLA Manufactured by 3D Printing Technique. In Proceedings of the 6th International Conference and Exhibition on Sustainable Energy and Advanced Materials, Surakarta, Indonesia, 16-17 October 2019; Springer: Singapore, 2020; pp. 811-818.

41. Tymrak, B.; Kreiger, M.; Pearce, J. Mechanical properties of components fabricated with open-source 3-D printers under realistic environmental conditions. Mater. Des. 2014, 58, 242-246. [CrossRef]

42. Lanzotti, A.; Grasso, M.; Staiano, G.; Martorelli, M. The impact of process parameters on mechanical properties of parts fabricated in PLA with an open-source 3-D printer. Rapid Prototyp. J. 2015, 21, 604-617. [CrossRef]

43. Torres, J.; Cotelo, J.; Karl, J.; Gordon, A.P. Mechanical property optimization of FDM PLA in shear with multiple objectives. Jom 2015, 67, 1183-1193. [CrossRef]

44. Li, H.; Wang, T.; Sun, J.; Yu, Z. The effect of process parameters in fused deposition modelling on bonding degree and mechanical properties. Rapid Prototyp. J. 2018, 24, 80-92. [CrossRef]

45. Torres, J.; Cole, M.; Owji, A.; DeMastry, Z.; Gordon, A.P. An approach for mechanical property optimization of fused deposition modeling with polylactic acid via design of experiments. Rapid Prototyp. J. 2016, 22, 387-404. [CrossRef]

46. Liu, X.; Zhang, M.; Li, S.; Si, L.; Peng, J.; Hu, Y. Mechanical property parametric appraisal of fused deposition modeling parts based on the gray Taguchi method. Int. J. Adv. Manuf. Technol. 2017, 89, 2387-2397. [CrossRef]

47. Abbas, T.; Othman, F.M.; Ali, H.B. Effect of infill Parameter on compression property in FDM Process. Int. J. Eng. Res. Appl. 2017, 7, 16-19.

48. Abeykoon, C.; Sri-Amphorn, P.; Fernando, A. Optimization of fused deposition modeling parameters for improved PLA and ABS 3D printed structures. Int. J. Light. Mater. Manuf. 2020, 3, 284-297. [CrossRef]

49. Galeja, M.; Hejna, A.; Kosmela, P.; Kulawik, A. Static and Dynamic Mechanical Properties of 3D Printed ABS as a Function of Raster Angle. Materials 2020, 13, 297. [CrossRef] 
50. Guimarães, A.L.A.; Neto, V.G.; Foschini, C.R.; Azambuja, M.D.A.; Hellmeister, L.A.V. Influence of ABS print parameters on a 3D open-source, self-replicable printer. Rapid Prototyp. J. 2020, 26, 1733-1738. [CrossRef]

51. Dwiyati, S.T.; Kholil, A.; Riyadi, R.; Putra, S.E. Influence of layer thickness and 3D printing direction on tensile properties of ABS material. J. Phys. Conf. Ser. 2019, 1402, 066014. [CrossRef]

52. Isaac, J.P.; Dondeti, S.; Tippur, H.V. Fracture behavior of additively printed ABS: Effects of print architecture and loading rate. Int. J. Solids Struct. 2021, 212, 80-95. [CrossRef]

53. Fernandez-Vicente, M.; Calle, W.; Ferrandiz, S.; Conejero, A. Effect of infill parameters on tensile mechanical behavior in desktop 3D printing. 3D Print. Addit. Manuf. 2016, 3, 183-192. [CrossRef]

54. Alvarez, K.L.C.; Lagos, R.F.C.; Aizpun, M. Investigating the influence of infill percentage on the mechanical properties of fused deposition modelled ABS parts. Ing. E Investig. 2016, 36, 110-116. [CrossRef]

55. Wang, P.; Zou, B.; Xiao, H.; Ding, S.; Huang, C. Effects of printing parameters of fused deposition modeling on mechanical properties, surface quality, and microstructure of PEEK. J. Mater. Process. Technol. 2019, 271, 62-74. [CrossRef]

56. Deng, X.; Zeng, Z.; Peng, B.; Yan, S.; Ke, W. Mechanical properties optimization of poly-ether-ether-ketone via fused deposition modeling. Materials 2018, 11, 216. [CrossRef] [PubMed]

57. Motaparti, K.P. Effect of Build Parameters on Mechanical Properties of Ultem 9085 Parts by Fused Deposition Modeling. Master's Thesis, Missouri University of Science and Technology, Rolla, MO, USA, 2016. Available online: https://scholarsmine.mst.edu/ masters_theses/7513 (accessed on 1 May 2021).

58. Liaw, C.-Y.; Tolbert, J.W.; Chow, L.W.; Guvendiren, M. Interlayer bonding strength of 3D printed PEEK specimens. Soft Matter 2021, 17, 4775-4789. [CrossRef] [PubMed]

59. Dev, S.; Srivastava, R. Effect of infill parameters on material sustainability and mechanical properties in fused deposition modelling process: A case study. Prog. Addit. Manuf. 2021, 1-12. [CrossRef]

60. Srinivasan, R.; Ruban, W.; Deepanraj, A.; Bhuvanesh, R. Effect on infill density on mechanical properties of PETG part fabricated by fused deposition modelling. Mater. Today Proc. 2020, 27, 1838-1842. [CrossRef]

61. Srinivasan, R.; Kumar, K.N.; Ibrahim, A.J.; Anandu, K.; Gurudhevan, R. Impact of fused deposition process parameter (infill pattern) on the strength of PETG part. Mater. Today Proc. 2020, 27, 1801-1805. [CrossRef]

62. Teraiya, S.; Vyavahare, S.; Kumar, S. Experimental Investigation on Influence of Process Parameters on Mechanical Properties of PETG Parts Made by Fused Deposition Modelling. In Advances in Manufacturing Processes; Springer: Singapore, $2021 ;$ pp. 283-293.

63. Hsueh, M.-H.; Lai, C.-J.; Wang, S.-H.; Zeng, Y.-S.; Hsieh, C.-H.; Pan, C.-Y.; Huang, W.-C. Effect of Printing Parameters on the Thermal and Mechanical Properties of 3D-Printed PLA and PETG, Using Fused Deposition Modeling. Polymers 2021, 13, 1758. [CrossRef]

64. A Standard: "ISO/ASTM 52900: 2015 Additive Manufacturing-General Principles-Terminology"; ASTM F2792-10e1; ASTM International: West Conshohocken, PA, USA, 2015.

65. ASTM-D638: "Standard Test Method for Tensile Properties of Plastics"; ASTM International: West Conshohocken, PA, USA, 2010.

66. ISO/ASTM:"Standard Terminology for Additive Manufacturing-Coordinate Systems and Test Methodologies"; ASTM International: West Conshohocken, PA, USA, 2013.

67. Dey, A.; Yodo, N. A Systematic Survey of FDM Process Parameter Optimization and Their Influence on Part Characteristics. J. Manuf. Mater. Process. 2019, 3, 64. [CrossRef]

68. Lee, C.; Kim, S.; Kim, H.; Ahn, S. Measurement of anisotropic compressive strength of rapid prototyping parts. J. Mater. Process. Technol. 2007, 187, 627-630. [CrossRef]

69. Vyavahare, S.; Teraiya, S.; Panghal, D.; Kumar, S. Fused deposition modelling: A review. Rapid Prototyp. J. 2019, $26,176-201$. [CrossRef]

70. Tsiolikas, A.; Mikrou, T.; Vakouftsi, F.; Aslani, K.-E.; Kechagias, J. (Ioannis) Robust design application for optimizing ABS fused filament fabrication process: A case study. IOP Conf. Ser. Mater. Sci. Eng. 2019, 564, 012021. [CrossRef]

71. Li, H.; Wang, T.; Yu, Z. The Quantitative Research of Interaction between Key Parameters and the Effects on Mechanical Property in FDM. Adv. Mater. Sci. Eng. 2017, 2017, 1-15. [CrossRef]

72. Pagano, C.; Basile, V.; Modica, F.; Fassi, I. Micro-FDM process capability and post-processing effects on mechanical properties. In AIP Conference Proceedings; AIP Publishing LLC: Melville, NY, USA, 2019; Volume 2139, p. 190002.

73. Montero, M.; Roundy, S.; Odell, D.; Ahn, S.-H.; Wright, P.K. Material characterization of fused deposition modeling (FDM) ABS by designed experiments. Soc. Manuf. Eng. 2001, 10, 1-21.

74. Basile, V.; Modica, F.; Fontana, G.; Ruggeri, S.; Fassi, I. Improvements in accuracy of fused deposition modeling via integration of low-cost on-board vision systems. J. Micro Nano-Manuf. 2020, 8. [CrossRef]

75. Chacón, J.; Caminero, M.A.; García-Plaza, E.; Núnez, P.J. Additive manufacturing of PLA structures using fused deposition modelling: Effect of process parameters on mechanical properties and their optimal selection. Mater. Des. 2017, 124, 143-157. [CrossRef]

76. Ahmed, A.; Susmel, L. A material length scale-based methodology to assess static strength of notched additively manufactured polylactide (PLA). Fatigue Fract. Eng. Mater. Struct. 2018, 41, 2071-2098. [CrossRef]

77. Zhang, X.; Chen, L.; Mulholland, T.; Osswald, T.A. Effects of raster angle on the mechanical properties of PLA and Al/PLA composite part produced by fused deposition modeling. Polym. Adv. Technol. 2019, 30, 2122-2135. [CrossRef] 
78. Cho, E.E.; Hein, H.H.; Lynn, Z.; Hla, S.J.; Tran, T. Investigation on influence of infill pattern and layer thickness on mechanical strength of PLA material in 3D printing technology. J. Eng. Sci. Res. 2019, 3, 27-37.

79. Luzanin, O.; Movrin, D.; Stathopoulos, V.; Pandis, P.; Radusin, T.; Guduric, V. Impact of processing parameters on tensile strength, in-process crystallinity and mesostructure in FDM-fabricated PLA specimens. Rapid Prototyp. J. 2019, 25, 1398-1410. [CrossRef]

80. Zhao, Y.; Chen, Y.; Zhou, Y. Novel mechanical models of tensile strength and elastic property of FDM AM PLA materials: Experimental and theoretical analyses. Mater. Des. 2019, 181, 108089. [CrossRef]

81. Rodríguez-Panes, A.; Claver, J.; Camacho, A.M. The Influence of Manufacturing Parameters on the Mechanical Behaviour of PLA and ABS Pieces Manufactured by FDM: A Comparative Analysis. Materials 2018, 11, 1333. [CrossRef] [PubMed]

82. Rismalia, M.; Hidajat, S.C.; Permana, I.G.R.; Hadisujoto, B.; Muslimin, M.; Triawan, F. Infill pattern and density effects on the tensile properties of 3D printed PLA material. J. Phys. Conf. Ser. 2019, 1402, 044041. [CrossRef]

83. Mazurchevici, A.-D.; Popa, R.-I.; Carausu, C.; Mazurchevici, S.-N.; Nedelcu, D. Influence of Layer Thickness, Infill Rate and Orientation on Thermal and Structural Loading of FDM Parts. In Advances in Manufacturing Processes; Springer: Berlin/Heidelberg, Germany, 2021; pp. 263-282.

84. Chandravadia, M.R.; Chudasama, M.K. Experimental Investigation on Tensile Properties of Nylon Glass Fibre Material Made Using Fused Deposition Modelling Process. In Advances in Manufacturing Processes; Springer: Berlin/Heidelberg, Germany, 2021; pp. 329-342.

85. Murugan, R.; Mitilesh, R.N.; Singamneni, S. Influence of process parameters on the mechanical behaviour and processing time of 3D printing. Int. J. Mod. Manuf. Technol. 2019, 1, 21-27.

86. Dave, H.K.; Rajpurohit, S.R.; Patadiya, N.H.; Dave, S.J.; Kumar, S.; Sharma; Thambad, S.S.; Srinivasn, V.P.; Sheth, K. Compressive strength of PLA based scaffolds: Effect of layer height, infill density and print speed. Int. J. Mod. Manuf. Technol. 2019, 11, 21-27.

87. Fatimatuzahraa, A.; Farahaina, B.; Yusoff, W. The Effect of Employing Different Raster Orientations on the Mechanical Properties and Microstructure of Fused Deposition Modeling Parts. In Proceedings of the 2011 IEEE Symposium on Business, Engineering and Industrial Applications (ISBEIA), Langkawi, Malaysia, 25-28 September 2011; pp. 22-27.

88. Sharma, M.; Ziemian, C. Anisotropic mechanical properties of ABS parts fabricated by fused deposition modelling. Mech. Eng. 2012, 23, 2397. [CrossRef]

89. Ziemian, S.; Okwara, M.; Ziemian, C.W. Tensile and fatigue behavior of layered acrylonitrile butadiene styrene. Rapid Prototyp. J. 2015, 21, 270-278. [CrossRef]

90. Rankouhi, B.; Javadpour, S.; Delfanian, F.; Letcher, T. Failure Analysis and Mechanical Characterization of 3D Printed ABS With Respect to Layer Thickness and Orientation. J. Fail. Anal. Prev. 2016, 16, 467-481. [CrossRef]

91. Nomani, J.; Wilson, D.; Paulino, M.; Mohammed, M.I. Effect of layer thickness and cross-section geometry on the tensile and compression properties of 3D printed ABS. Mater. Today Commun. 2020, 22, 100626. [CrossRef]

92. Suaidi, S.N.S.W.; Azizul, M.A.; Sulaiman, S.; Hao, T.Y. Effect of fused deposition modelling process parameters on the quality of ABS product. J. Ind. Eng. Innov. 2020, 2, 9.

93. Baich, L.; Manogharan, G.; Marie, H. Study of infill print design on production cost-time of 3D printed ABS parts. Int. J. Rapid Manuf. 2015, 5, 308. [CrossRef]

94. Yadav, D.; Chhabra, D.; Garg, R.K.; Ahlawat, A.; Phogat, A. Optimization of FDM 3D printing process parameters for multimaterial using artificial neural network. Mater. Today Proc. 2020, 21, 1583-1591. [CrossRef]

95. Samykano, M.; Selvamani, S.K.; Kadirgama, K.; Ngui, W.K.; Kanagaraj, G.; Sudhakar, K. Mechanical property of FDM printed ABS: Influence of printing parameters. Int. J. Adv. Manuf. Technol. 2019, 102, 2779-2796. [CrossRef]

96. Abbott, A.; Tandon, G.; Bradford, R.; Koerner, H.; Baur, J. Process-structure-property effects on ABS bond strength in fused filament fabrication. Addit. Manuf. 2018, 19, 29-38. [CrossRef]

97. Domingo-Espin, M.; Travieso-Rodriguez, J.A.; Jerez-Mesa, R.; Lluma-Fuentes, J. Fatigue Performance of ABS Specimens Obtained by Fused Filament Fabrication. Materials 2018, 11, 2521. [CrossRef] [PubMed]

98. Rinaldi, M.; Cecchini, F.; Pigliaru, L.; Ghidini, T.; Lumaca, F.; Nanni, F. Additive Manufacturing of Polyether Ether Ketone (PEEK) for Space Applications: A Nanosat Polymeric Structure. Polymers 2020, 13, 11. [CrossRef]

99. Li, Y.; Lou, Y. Tensile and Bending Strength Improvements in PEEK Parts Using Fused Deposition Modelling 3D Printing Considering Multi-Factor Coupling. Polymers 2020, 12, 2497. [CrossRef]

100. Rinaldi, M.; Ghidini, T.; Cecchini, F.; Brandao, A.; Nanni, F. Additive layer manufacturing of poly (ether ether ketone) via FDM. Compos. Part B Eng. 2018, 145, 162-172. [CrossRef]

101. Wang, Y.; Müller, W.-D.; Rumjahn, A.; Schmidt, F.; Schwitalla, A.D. Mechanical properties of fused filament fabricated PEEK for biomedical applications depending on additive manufacturing parameters. J. Mech. Behav. Biomed. Mater. 2021, 115, 104250. [CrossRef]

102. Basgul, C.; Yu, T.; MacDonald, D.W.; Siskey, R.; Marcolongo, M.; Kurtz, S.M. Does annealing improve the interlayer adhesion and structural integrity of FFF 3D printed PEEK lumbar spinal cages? J. Mech. Behav. Biomed. Mater. 2020, 102, 103455. [CrossRef]

103. Mercado-Colmenero, J.M.; La Rubia, M.D.; Mata-Garcia, E.; Rodriguez-Santiago, M.; Martin-Doñate, C. Experimental and Numerical Analysis for the Mechanical Characterization of PETG Polymers Manufactured with FDM Technology under Pure Uniaxial Compression Stress States for Architectural Applications. Polymers 2020, 12, 2202. [CrossRef] 
104. Messimer, S.L.; Pereira, T.R.; Patterson, A.E.; Lubna, M.; Drozda, F.O. Full-Density Fused Deposition Modeling Dimensional Error as a Function of Raster Angle and Build Orientation: Large Dataset for Eleven Materials. J. Manuf. Mater. Process. 2019, 3, 6. [CrossRef]

105. Dolzyk, G.; Jung, S. Tensile and Fatigue Analysis of 3D-Printed Polyethylene Terephthalate Glycol. J. Fail. Anal. Prev. 2019, 19, 511-518. [CrossRef]

106. Durgashyam, K.; Reddy, M.I.; Balakrishna, A.; Satyanarayana, K. Experimental investigation on mechanical properties of PETG material processed by fused deposition modeling method. Mater. Today Proc. 2019, 18, 2052-2059. [CrossRef]

107. Srinivasan, R.; Prathap, P.; Raj, A.; Kannan, S.A.; Deepak, V. Influence of fused deposition modeling process parameters on the mechanical properties of PETG parts. Mater. Today Proc. 2020, 27, 1877-1883. [CrossRef]

108. Kumar, M.A.; Khan, M.; Mishra, S. Effect of machine parameters on strength and hardness of FDM printed carbon fiber reinforced PETG thermoplastics. Mater. Today Proc. 2020, 27, 975-983. [CrossRef] 